\title{
Representation of Boreal Winter MJO and Its Teleconnection in a Dynamical Ensemble Seasonal Prediction System
}

\author{
HYERIM KIM AND MYONG-IN LEE \\ Ulsan National Institute of Science and Technology, Ulsan, South Korea \\ DAEHYUN KIM \\ University of Washington, Seattle, Washington \\ HYUN-SUK KANG AND YU-KYUNG HYUN \\ Climate Research Laboratory, National Institute of Meteorological Research, Jeju, South Korea
}

(Manuscript received 22 January 2018, in final form 9 August 2018)

\begin{abstract}
This study examines the representation of the Madden-Julian oscillation (MJO) and its teleconnection in boreal winter in the Global Seasonal Forecast System, version 5 (GloSea5), using 20 years (1991-2010) of hindcast data. The sensitivity of the performance to the polarity of El Niño-Southern Oscillation (ENSO) is also investigated. The real-time multivariate MJO index of Wheeler and Hendon is used to assess MJO prediction skill while intraseasonal $200-\mathrm{hPa}$ streamfunction anomalies are used to evaluate the MJO teleconnection. GloSea5 exhibits significant MJO prediction skill up to 25 days of forecast lead time. MJO prediction skill in GloSea5 also depends on initial MJO phases, with relatively enhanced (degraded) performance when the initial MJO phase is 2 or 3 ( 8 or 1 ) during the first 2 weeks of the hindcast period. GloSea5 depicts the observed MJO teleconnection patterns in the extratropics realistically up to 2 weeks albeit weaker than the observed. The ENSO-associated basic-state changes in the tropics and in the midlatitudes are reasonably represented in GloSea5. MJO prediction skill during the first 2 weeks of the hindcast is slightly higher in neutral and La Niña years than in El Niño years, especially in the upper-level zonal wind anomalies. Presumably because of the better representation of MJO-related tropical heating anomalies, the Northern Hemispheric MJO teleconnection patterns in neutral and La Niña years are considerably better than those in El Niño years.
\end{abstract}

\section{Introduction}

The Madden-Julian oscillation (MJO; Madden and Julian 1971,1972) is the dominant mode of intraseasonal variability in the tropical atmosphere. The MJO features anomalous deep convection organized at the planetary scale and coupled to large-scale circulation anomalies. The MJO's eastward propagation is most prominent over the Indo-Pacific warm pool, where its phase speed is about $5 \mathrm{~m} \mathrm{~s}^{-1}$.

The MJO exerts numerous influences on weather and climate variability in the tropics and the subtropics. For instance, it affects the onset, development, and termination of El Niño-Southern Oscillation (ENSO; McPhaden 1999, 2004; Takayabu et al. 1999; Kessler and Kleeman

Corresponding author: Dr. Myong-In Lee, milee@unist.ac.kr
2000; Bergman et al. 2001; Zhang and Gottschalck 2002; Seo and Xue 2005) and the active and break episodes of the Asian-Australian monsoon (Yasunari 1979; Lau and Chan 1986). The genesis and track of tropical cyclones are also affected by MJO in the eastern North Pacific (Maloney and Hartmann 2000), the northwest Pacific (Maloney and Hartmann 2001; Schreck and Molinari 2011; D. Kim et al. 2014), and the North Atlantic (Klotzbach 2010).

By affecting the midlatitude weather via its teleconnection (Matthews et al. 2004; Seo and Lee 2017), the MJO is known as the dominant source of predictability in the intraseasonal time scale over midlatitudes (Pegion and Kirtman 2008). For example, weather phenomena over North America (Matthews et al. 2004; Zhou et al. 2012; Baxter et al. 2014; Johnson et al. 2014), South America (Roundy 2014) and East Asia 
(Jeong et al. 2008; Jia et al. 2011) are known to be affected by the MJO's teleconnection. Furthermore, the pattern of the MJO teleconnection changes by the phase of ENSO (Moon et al. 2011). ENSO alters background fields such as sea surface temperature and upperlevel wind, and this change affects the MJO variability as well as the mean state properties that are known to be important for wave propagation from the tropics to the midlatitudes. Moon et al. (2011) showed that the MJO teleconnection patterns during El Niño and $\mathrm{La}$ Niña years over extratropical regions differ distinctively even at the same MJO phase.

Research interest in the forecast at the subseasonal time scale (2-8 weeks) has been growing (Waliser et al. 2006) as it fills the gap between the short-range weather forecast and seasonal prediction (Vitart 2017). Contemporary operational dynamical predictions demonstrate skillful prediction skills of the MJO up to 10-34 days (Vitart 2017; Lim et al. 2018), although the forecasting systems have much room for improvement as their actual forecasting skill of MJO is still lower than the theoretical predictability limit of 25-40 days (Waliser et al. 2003; H.-M. Kim et al. 2014; Neena et al. 2014).

In examining ensemble prediction systems, numerous studies have investigated the sensitivity of MJO prediction skill to the season and the amplitude and phase of the MJO in the initial conditions. For instance, the skill is known to be in general higher during boreal winter and with a strong MJO signal in the initial conditions (Waliser et al. 2003; Reichler and Roads 2005; Kim and Kang 2008; Lin et al. 2008; Vitart and Molteni 2010; Vitart et al. 2010; Rashid et al. 2011; Zhang and Van den Dool 2012; Wang et al. 2014; H.-M. Kim et al. 2014; Vitart 2014; Wu et al. 2016). The MJO prediction skill is also affected by the phase of the ENSO (Seo 2009) due to the changes in the spatial distribution of sea surface temperature.

As stated above, the contemporary state-of-the-art forecast systems have a useful degree of MJO prediction skill, and this implies that the models could represent the modulation of midlatitude weather phenomena by the MJO if they offer significant prediction skill of the teleconnection pattern associated with the MJO. There are a handful of studies that assess the representation of the MJO teleconnection in midlatitudes in the hindcasts. For instance, Vitart and Molteni (2010) showed that the European Centre for Medium-Range Weather Forecasts (ECMWF) forecast system is capable of representing the MJO teleconnection in 500-hPa geopotential height anomalies up to forecast lead days of 19-25. Wu et al. (2016) demonstrated that the Beijing Climate Center Atmospheric General Circulation Model was capable of representing the observed influence of the
MJO on the occurrence frequency of the Arctic Oscillation (AO) and the North Atlantic Oscillation (NAO).

In this study, we examine the representation of the MJO and its teleconnection in the midlatitudes in an operational seasonal prediction system-the Global Seasonal Forecasting System, version 5 (GloSea5) with a particular emphasis on the sensitivity of the performance to the phase of ENSO. While previous studies have examined the sensitivity of MJO prediction skill to ENSO phase (e.g., Seo 2009), the dependency of the MJO teleconnection on ENSO phase in an operational prediction model has not been investigated.

The current manuscript is structured as follows. The data and methods used in this study are explained in section 2. Section 3 presents the performance of GloSea5 in regard to MJO prediction skill and the MJO teleconnection. The sensitivity of MJO prediction skill and MJO teleconnection fidelity in GloSea5 is also presented in Section 3. Section 4 summarizes the results and presents conclusions.

\section{Data and methods}

\section{a. GloSea5 hindcasts}

The hindcast dataset used in this study was produced using GloSea5, which was originally developed by the Met Office (UKMO) and implemented as the operational subseasonal-to-seasonal prediction system of the Korea Meteorological Administration (KMA). GloSea5 is a state-of-the-art ensemble prediction system that is fully coupled with atmosphere, land, surface, ocean, and sea ice components (Hewitt et al. 2011; Lee et al. 2014). In this study, the GloSea5 Global Coupled Model 2.0 (GC2.0) is used. This model consists of the Unified Model (UM; Walters et al. 2011; Brown et al. 2012) Global Atmosphere (GA), version 6.0, for the atmosphere, Nucleus for European Modeling of the Ocean (NEMO; Madec et al. 2016) Global Ocean (GO), version 5.0, for the ocean (Megann et al. 2014), the Joint U.K. Land Environment Simulator (JULES; Best et al. 2011) Global Land (GL), version 6.0, for land, and the Los Alamos Sea Ice Model (CICE; Hunke and Lipscomb 2010) Global Sea ice (GSI), version 6.0, for sea ice (Rae et al. 2015). These component models are coupled using the OASIS, version 3, coupler (Valcke 2013).

The horizontal and vertical resolutions of GloSea5 for the atmosphere are $\mathrm{N} 216\left(0.556^{\circ}\right.$ latitude $\times 0.833^{\circ}$ longitude, approximately $\sim 60 \mathrm{~km}$ ) and L85 (85 vertical levels capped at $85 \mathrm{~km}$ above sea level), respectively. In the ocean model, horizontal resolution is $0.25^{\circ}$ except for near the equator $\left(20^{\circ} \mathrm{S}-20^{\circ} \mathrm{N} ; 13^{\circ}\right)$, and it has 75 vertical levels. GloSea5 GC2.0 hindcasts consist of $20-\mathrm{yr}$ 
(1991-2010) ensemble predictions starting on the 1st, 9 th, 17 th, and 25 th of each month and integrated for 7 months. Each starting day of the hindcasts has three ensembles perturbed by the stochastic kinetic energy backscatter scheme, version 2 (SKEB2; Shutts 2005; Tennant et al. 2011). Detailed descriptions of the GloSea system, especially GloSea5 GC2.0, and its hindcast data are found in MacLachlan et al. (2015), Williams et al. (2015), and Walters et al. (2017).

When adopted by the KMA, the following modifications to the GloSea5 seasonal prediction system were made: (i) the number of ensembles produced by SKEB2 is seven from the UKMO but three from the KMA and (ii) hindcasts from the UKMO and the KMA cover from 1993 to 2015 (23 years) and from 1991 to 2010 (20 years), respectively. Hereafter, GloSea5 refers to the KMA version of the prediction system.

\section{b. Observations}

For the validation of model hindcasts, the daily Advanced Very High Resolution Radiometer (AVHRR) satellite data from the National Oceanic and Atmospheric Administration (NOAA) for outgoing longwave radiation (OLR), along with daily Modern-Era Retrospective Analysis for Research and Applications (MERRA) reanalysis data from the National Aeronautics and Space Administration's (NASA) Global Modeling and Assimilation Office (GMAO) for upper $(200 \mathrm{hPa})$ and lower-level $(850 \mathrm{hPa})$ wind fields, are used. The native horizontal resolution is $2.5^{\circ}$ latitude $\times$ $2.5^{\circ}$ longitude for AVHRR OLR and $1.25^{\circ}$ latitude $\times$ $1.25^{\circ}$ longitude for MERRA. The observation and the hindcast data were analyzed on common grids of $2.5^{\circ}$ latitude $\times 2.5^{\circ}$ longitude resolution by linear interpolation. Note that our examination exclusively focuses on boreal winter (November-March), when the tropical MJO and its extratropical teleconnection are most pronounced during the year.

\section{c. Methods}

The Real-Time Multivariate MJO (RMM) index used in this study was developed by Wheeler and Hendon (2004), who used the combined empirical orthogonal function (EOF) analysis for OLR and zonal winds at 850 and $200 \mathrm{hPa}$. Following Gottschalck el al. (2010), the climatological-mean fields of each variable obtained from the hindcast data starting at each date and the observation data are removed first to create the anomaly fields. The interannual variability associated with ENSO is removed by subtracting the 120-day moving average in the time series. The observed values are used to obtain the 120-day moving average when the model data are unavailable for the initial times.
The anomaly fields are then averaged over $15^{\circ} \mathrm{S}-15^{\circ} \mathrm{N}$. The averaged fields are divided by the normalization factors provided in Wheeler and Hendon (2004), which are $15.11623 \mathrm{~W} \mathrm{~m}^{-2}, 1.81355 \mathrm{~m} \mathrm{~s}^{-1}$, and $4.80978 \mathrm{~m} \mathrm{~s}^{-1}$ for OLR, 850-hPa zonal wind (U850), and 200-hPa zonal wind (U200), respectively. These normalized fields are projected onto the observed EOFs given by the Australian Bureau of Meteorology (http://www.hom.gov.au/ climate/mjo) to produce the principal component (PC) time series. The final RMM1 (RMM2) time series are obtained by dividing the PC time series that correspond to the first (second) EOF by the standard deviation of the observed time series.

The MJO amplitude and phase are defined as $\left(\mathrm{RMM}^{2}+\right.$ $\left.\mathrm{RMM}^{2}\right)^{1 / 2}$ and $\tan ^{-1}$ (RMM2/RMM1), respectively. This study uses 1.0 as a criterion of MJO amplitude, and MJO cases with amplitudes higher and lower than 1.0 are classified as well- and less-developed cases, respectively. Two metrics of the MJO prediction skill are used, the bivariate anomaly correlation coefficient (ACC) and the rootmean-square error (RMSE), as in Rashid et al. (2011) and Gottschalck et al. (2010).

MJO phase composite maps of intraseasonal (3070 -day filtered) streamfunction anomalies at $200 \mathrm{hPa}$ (SF200) are used to examine the MJO teleconnection patterns (e.g., Figs. 6 and 7). For the hindcast dataset, the filtering is performed after the hindcast dataset of similar lead time is concatenated. For example, the week 1 hindcast time series is created by concatenating all hindcasts for days $1-8$. In a same manner, the week 2 and 3 time series is obtained for days 9-16, and the week 3 time series is for days 17-24, successively. Since the hindcast time series is started on the 1st, 9th, 17th, and 25 th of every month, the resulting concatenated time series spans the entire time period (1991-2010). The seasonal cycle is removed from each concatenated time series by eliminating the first three harmonics in each grid point. A Lanczos filter is then applied to extract anomalies with a 30-70-day period. To facilitate a quantitative assessment, we calculate the spatial correlation coefficients between the SF200 anomaly composite map in GloSea5 and the corresponding observed pattern as our metric of MJO teleconnection fidelity (e.g., Fig. 8). The spatial correlation coefficients are calculated over the Northern Hemisphere $\left(15^{\circ}-80^{\circ} \mathrm{N}\right.$, $\left.0^{\circ}-360^{\circ}\right)$.

Finally, the definitions of El Niño and La Niña years are based on the Niño-3.4 SST index provided by the Climate Prediction Center (CPC), where 1991, 1994, 1997, 2002, 2004, 2006, and 2009 are selected for El Niño; 1995, 1998, 1999, 2000, and 2007 for La Niña; and 1992, 1993, 1996, 2001, 2003, 2005, and 2008 for the neutral years, respectively. 

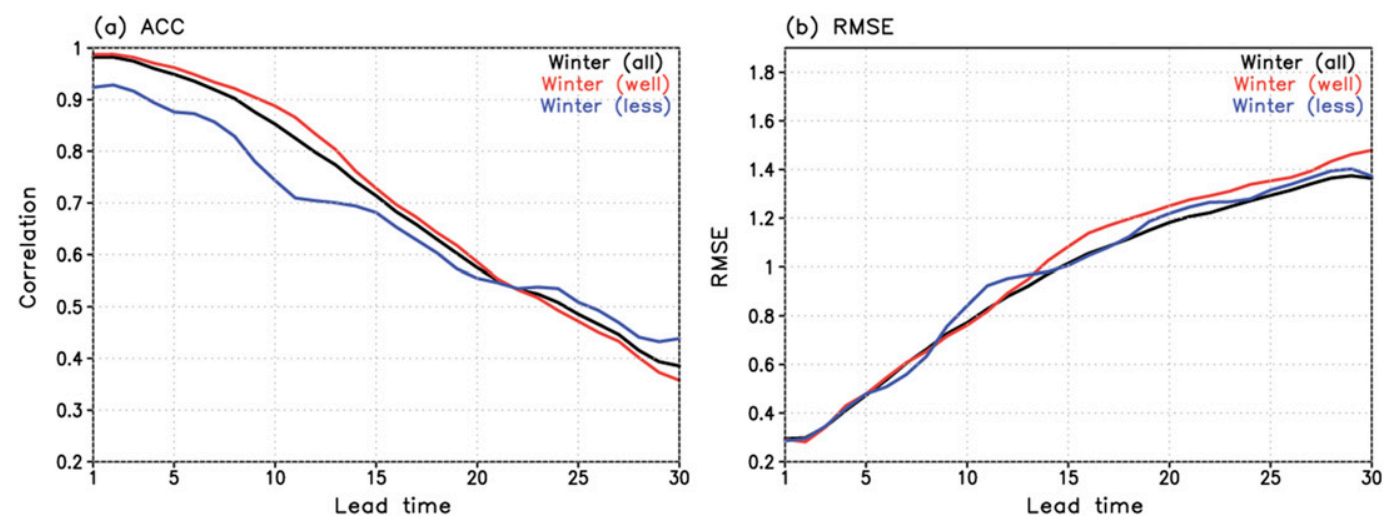

FIG. 1. Bivariate (a) ACCs and (b) RMSEs of GloSea5 RMM indices as a function of forecast lead time. Bivariate ACCs and RMSEs are obtained by using all MJO cases (black), and well- (red) and less-developed (blue) MJO cases for boreal winter (November-March).

\section{Results}

\section{a. MJO prediction skill and MJO teleconnection in GloSea5 hindcast}

We begin by analyzing MJO prediction skill and MJO teleconnection performance in GloSea5 hindcasts using the all-year dataset. Later (section 3c), a similar skill assessment will be performed separately for three ENSO phases: El Niño, La Niña, and neutral. The results presented in this section will provide the basis for the following analysis and for a comparison with the skill of other models reported in previous studies. Figure 1 shows MJO prediction skill in GloSea5 represented as the bivariate ACC and RMSE. GloSea5 shows a significant degree of prediction skill (ACC $>0.5)$ at up to 23 days of forecast lead time, which is comparable to the results for other contemporary operational dynamical prediction models (Vitart 2017; Lim et al. 2018). As mentioned in the introduction, the level of skill in the S2S models ranges from 10 to 36 days (Vitart 2017; Lim et al. 2018). When the hindcasts are grouped into the less- and well-developed MJO categories, the ACC skill is higher in the well-developed MJO cases than in the less-developed cases, especially during the first 3 weeks of the hindcast period although the difference between the two cases in RMSE skill is negligible (Fig. 1). This sensitivity of the MJO forecast skill to the initial strength of the MJO is consistent with the other model results (e.g., Rashid et al. 2011; H.-M. Kim et al. 2014).

The sensitivity of the MJO prediction skill to the initial MJO phase is investigated in Fig. 2. The MJO phase is related to the location of the anomalously enhanced convection, consisting of eight phases. For instance, the MJO-associated anomalous tropical convection is located over the Indian Ocean in MJO phases 2 and 3, over the Maritime Continent in phases 4 and 5, over the western Pacific in phases 6 and 7, and over the Western Hemisphere and Africa in phases 8 and 1 (Wheeler et al. 2009). While the MJO prediction skill in GloSea5 does not show much dependence on the initial MJO phase, the skill is relatively higher with the initial MJO phases 2 and 3 and relatively lower with phases 8 and 1 , especially during the first 2 weeks of forecast lead time (Fig. 2). The results presented in Fig. 2 suggest that the so-called Maritime Continent MJO prediction barrier, which has been reported in a few of the models (e.g., H.-M. Kim et al. 2014; Neena et al. 2014; Wang et al. 2014; Xiang et al. 2015), does not appear in GloSea5.

To identify the relative contributions from the three variables used in the calculation of the RMM indexOLR, U850, and U200 - to the overall MJO prediction skill, RMM1 and RMM2 are reconstructed using only one of the three variables in the observations and in the

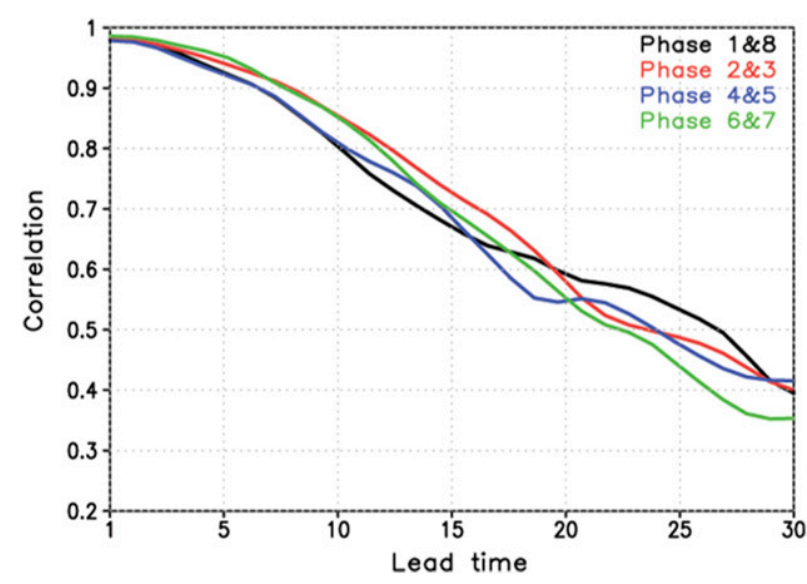

FIG. 2. Bivariate ACCs of GloSea5 RMM indices at the initial MJO phase for boreal winter as a function of forecast lead time. Black, red, blue, and green lines indicate initial MJO phase 1 and 8 , 2 and 3, 4 and 5, and 6 and 7, respectively. 


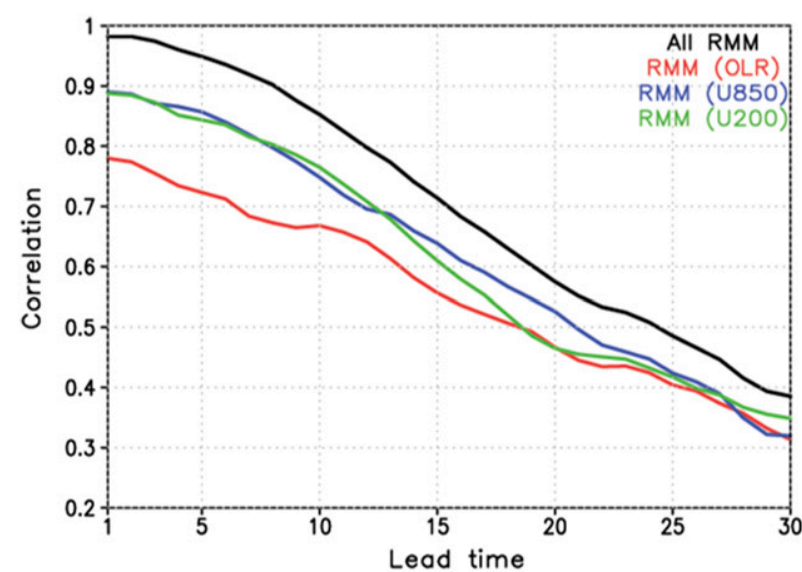

FIG. 3. Bivariate ACCs of GloSea5 RMM indices during boreal winter as a function of forecast lead time. Different colors indicate the results obtained using the original RMM indices (black) and reconstructed RMM indices using only OLR (red), 850-hPa zonal wind (blue), and 200-hPa zonal wind (green).

GloSea5 hindcast, and then the bivariate ACC metric is obtained for each of the reconstructed RMM indices (Fig. 3). The results show that the reconstructed RMM indices with the wind variables $\left(\mathrm{RMM}_{\mathrm{U} 850}\right.$ and $\mathrm{RMM}_{\mathrm{U} 200}$ ) show higher prediction skill than those with OLR $\left(\mathrm{RMM}_{\mathrm{OLR}}\right)$. This suggests that GloSea5 is more proficient in simulating wind anomalies than anomalous convection associated with the MJO. Similar behavior was reported by H.-M. Kim et al. (2014) for the ECMWF and NCEP hindcast datasets. Therefore, improving the representation of the convective anomalies associated with MJO may improve the MJO prediction skill significantly in the operational dynamical prediction models.

Figure 4 presents the composite near-equatorial $\left(10^{\circ} \mathrm{S}-10^{\circ} \mathrm{N}\right)$ OLR and U850 anomalies during the first 25 days of forecast lead time for hindcasts with initial MJO phases 3 and 7. The case of initial MJO phase 3 shows that strong convective anomalies are over the Indian Ocean and the low-level westerly and easterly anomalies converging toward the convection maximum at the initial times. The anomalous convection and wind migrate eastward over time, maintaining their coherent structure. On the other hand, the case of initial MJO phase 7 shows the suppressed convection anomalies located over the Indian Ocean and the Maritime Continent, and active convective anomalies over the western and central Pacific. The westerly and easterly winds occur over the eastern and western regions of the suppressed convection, respectively. Again, these suppressed convection and wind anomalies tend to propagate eastward for about 25 days after the start day. GloSea5 reproduces the observed eastward-propagating patterns of OLR and U850 realistically with reasonable intensity up to about 10-15 days of forecast lead time, after which the amplitude of the convective and (a) Observation (Phase 3)

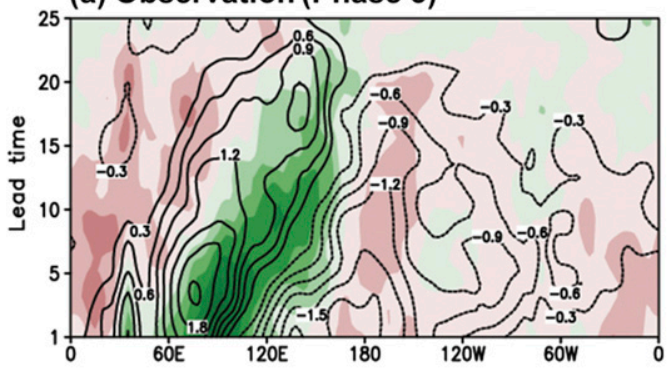

(c) Observation (Phase 7)

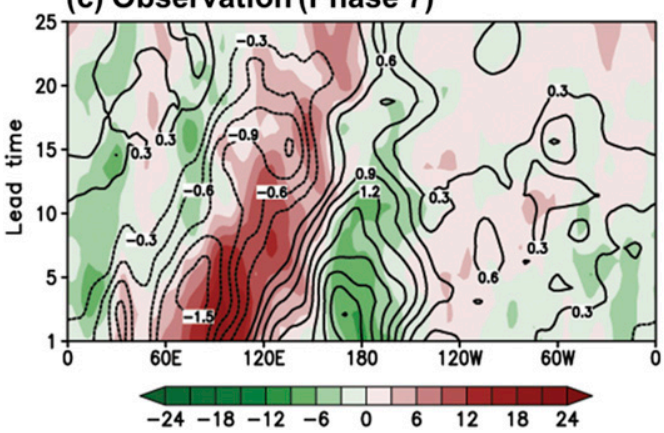

(b) GloSea5 (Phase 3)

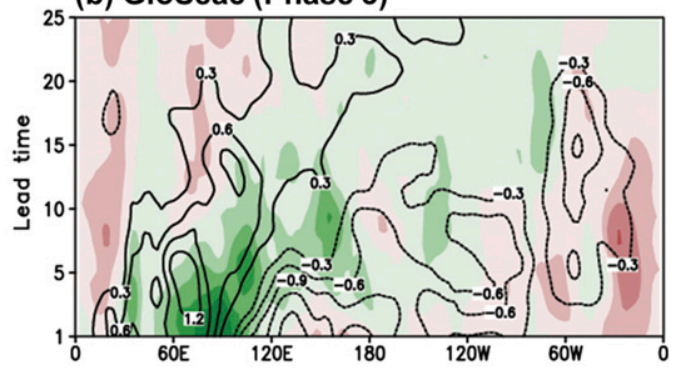

(d) GloSea5 (Phase 7)

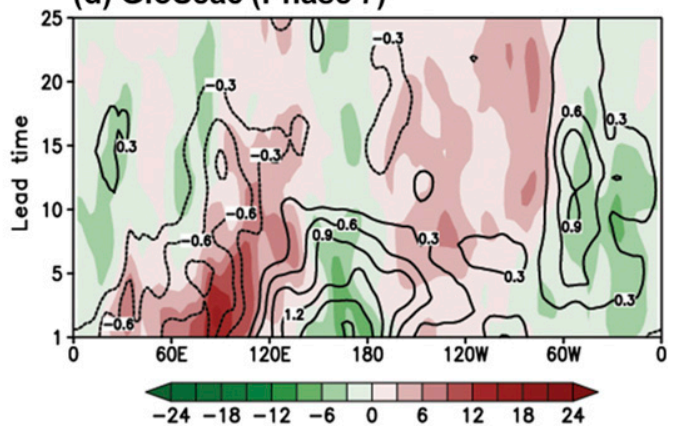

FIG. 4. Composite evolution of $10^{\circ} \mathrm{S}-10^{\circ} \mathrm{N}$ averaged OLR (shading; $\mathrm{W} \mathrm{m}^{-2}$ ) and $850-\mathrm{hPa}$ zonal wind (contours; $\mathrm{m} \mathrm{s}^{-1}$ ) anomalies obtained from (a),(c) the observations and (b),(d) GloSea5 at initial MJO phases (top) 3 and (bottom) 7 during the boreal cold season. The results are calculated using all MJO cases. 


\section{(a) Observation}

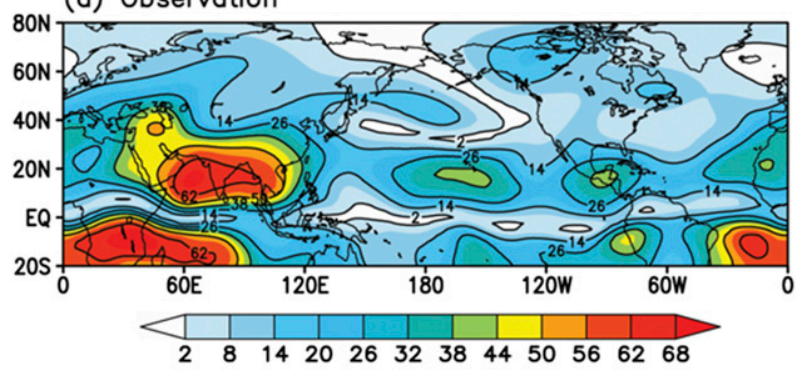

(b) GloSea5

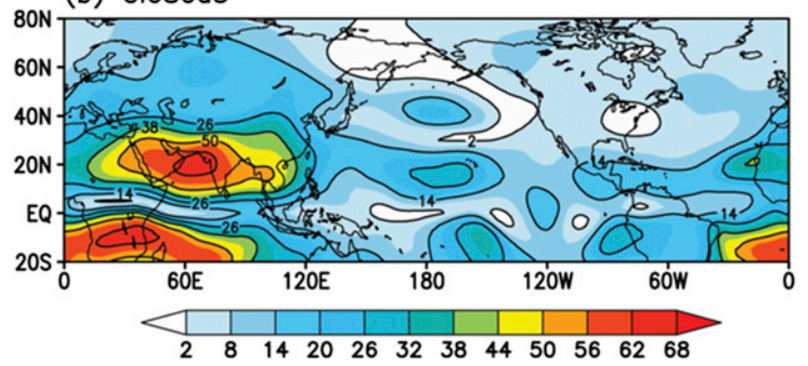

FIG. 5. The percentage variance of 30-70-day filtered streamfunction anomalies at $200 \mathrm{hPa}$ accounted for by the RMM index during boreal winter (November-March) from (a) the observations and (b) GloSea5 week 2. The percentage variance is defined as corr(RMM1, SF200) ${ }^{2}+\operatorname{corr}(\mathrm{RMM} 2, \mathrm{SF} 200)^{2}$, multiplied by 100.

low-level zonal wind anomalies become significantly weaker. Moreover, the OLR and U850 anomalies show a standing or westward-propagating pattern after about 2 weeks of lead time, which is in stark contrast to the observed anomalies.

Before examining the patterns of the MJO teleconnection for individual MJO phases, the extent to which the extratropical, upper-level circulation is modulated

(a) Observation (Phase 3)

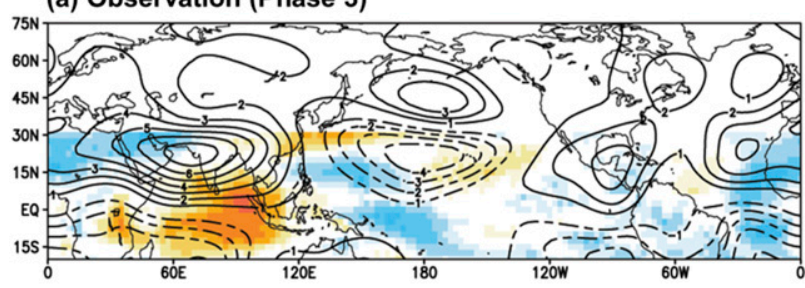

(c) GloSea5 Week 2 (Phase 3)

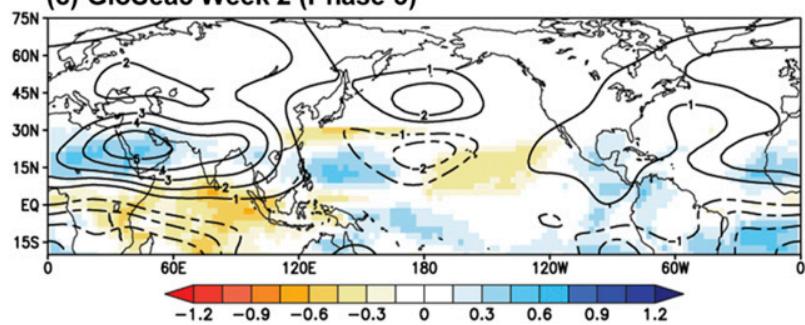

by the MJO is examined. Figure 5 shows the spatial distribution of the percentage variance of intraseasonal SF200 anomalies that is associated with the RMM index. Both in the observations and in GloSea5, the percentage variance map shows peaks in the tropical and subtropical Eastern Hemisphere, particularly over the tropical IndoPacific warm pool region, where the MJO-related convection is most active. The percentage variance decreases in the Western Hemisphere, as the MJO intensity becomes weaker and it propagates mostly as a dry signal from the date line to the African continent. The percentage variance becomes lower in the midlatitudes, with a number of notable local peaks in the North Pacific, Alaska, and the northeastern part of North America. This suggests that the MJO produces upper-level circulation anomalies through teleconnection over the extratropics. The relationship between the MJO and upper-level circulation anomalies in the GloSea5 hindcast is overall consistent with the observed results, although the percentage variance is lower than observed, suggesting a weaker MJO teleconnection.

MJO teleconnection patterns for initial MJO phases 3 and 7 in the observations and in GloSea5 are presented in Figs. 6 and 7, respectively. The two initial MJO phases are chosen to facilitate a comparison with other modeling studies (e.g., Yoo et al. 2015, see their Figs. 3 and 4 ), and we focus on the initially well-developed case. In the observations, the teleconnection pattern for MJO phase 3 in the Northern Hemisphere features the subtropical anticyclonic circulation anomalies in South Asia and the wave train that propagates from the subtropical central Pacific Ocean to North America. Seo and Lee (2017) suggested that this pattern of circulation anomalies could be explained by linear stationary Rossby wave

(b) GloSea5 Week 1 (Phase 3)

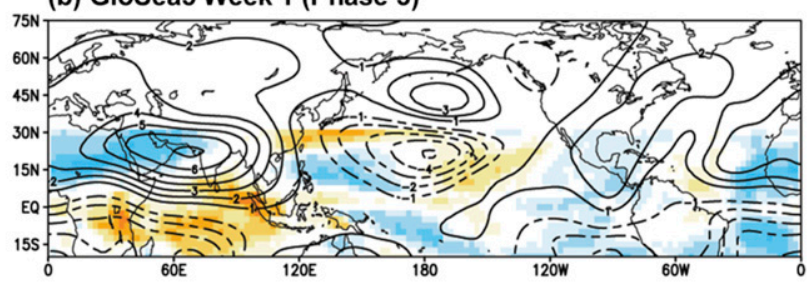

(d) GloSea5 Week 3 (Phase 3)

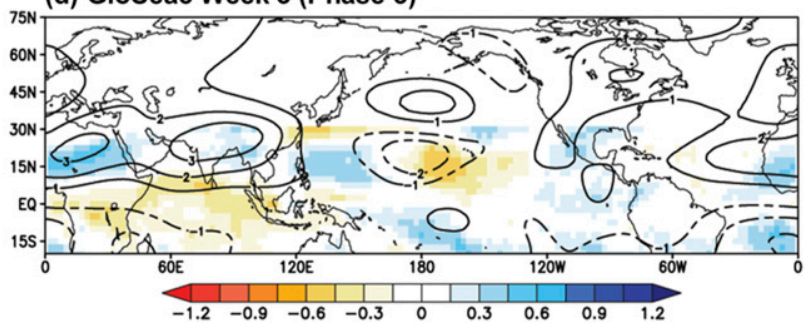

FIG. 6. The composite of OLR (shading; $\mathrm{W} \mathrm{m}^{-2}$ ) and streamfunction at $200 \mathrm{hPa}$ (contours; $10^{-6} \mathrm{~m} \mathrm{~s}^{-1}$ ) anomalies from (a) the observations and (b)-(d) GloSea5 weeks 1-3 at MJO phase 3 during all years in boreal winter. Each variable was filtered for 30-70 days. 
(a) Observation (Phase 7)

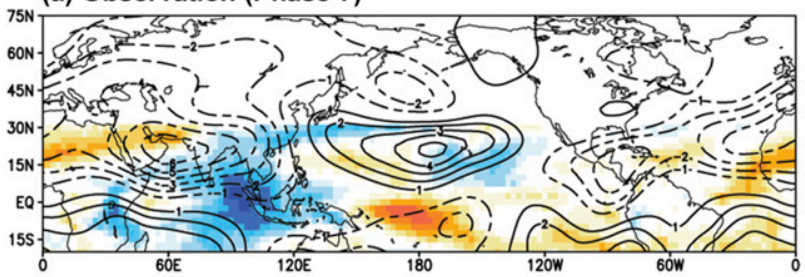

(c) GloSea5 Week 2 (Phase 7)

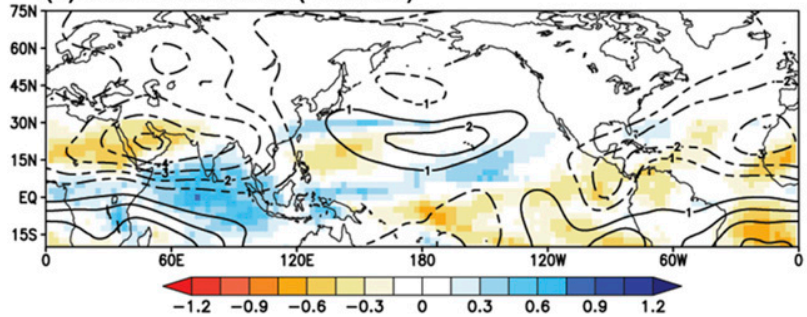

(b) GloSea5 Week 1 (Phase 7)

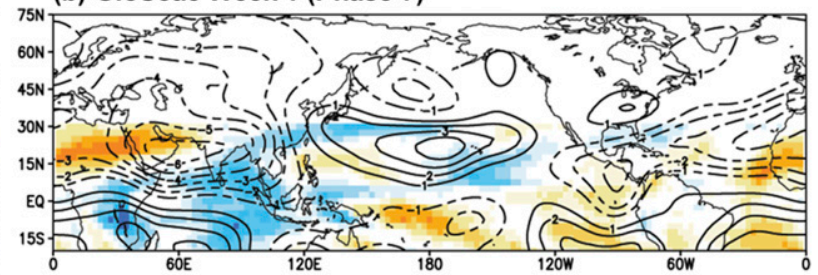

(d) GloSea5 Week 3 (Phase 7)

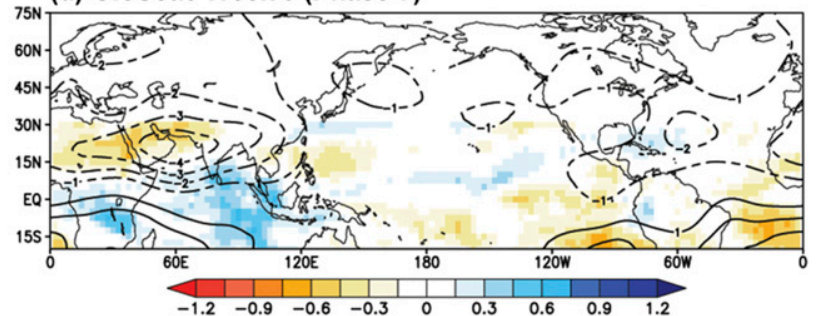

FIG. 7. As in Fig. 6, but for MJO phase 7.

theory (Hoskins and Karoly 1981; Hoskins and Ambrizzi 1993). In that explanation, the Rossby wave source (Sardeshmukh and Hoskins 1988) associated with the MJOrelated anomalous diabatic heating excites the Rossby waves, and the wave trains are formed following the group velocity of the Rossby waves. The teleconnection pattern for MJO phase 7 shows a similar pattern, with an opposite polarity. In GloSea5, the patterns of the SF200 anomalies are almost identical to the observed result for week 1 for both MJO phases. The magnitudes of the SF200 and OLR anomalies become weaker in weeks 2 and 3, while the locations of the cyclonic and anticyclonic anomalous upper-level flow remain close to those in the observations.

Figure 8 shows the MJO teleconnection performance metric as a function of forecast lead time. To examine the impact of the initial MJO amplitude, the skill levels for the well- and the less-developed MJO cases are compared. When the MJO is well developed in the initial conditions, GloSea5 is able to maintain realistic MJO teleconnection patterns well beyond week 3 with a pattern correlation higher than 0.7. In the less-developed MJO cases, however, the spatial correlation metric drops quickly after week 1 . The lower performance in the lessdeveloped MJO cases is likely due to the MJO prediction skill being lower with weaker MJO amplitudes in the initial conditions (Fig. 1). In our analysis, the observed (simulated) ratios of well- and less-developed MJO cases are $66.99 \%$ (59.04\%) and 33.01\% (40.96\%), respectively.

\section{b. Changes in the basic state and tropical intraseasonal variability in response to ENSO}

In this section, our assessment of GloSea5 hindcasts focuses on the changes in the basic state and tropical intraseasonal variability in response to ENSO, which will be followed by an examination of MJO prediction skill and MJO teleconnection (section 3c). In our investigation of the basic state and tropical intraseasonal variability in GloSea5, we use the week 2 hindcast, as the MJO prediction skill drops below 0.7 and MJO teleconnection becomes significantly weaker after 2 weeks in GloSea5.

Figure 9 shows the winter-mean OLR and U200 climatology in the neutral years. It also shows the deviation of the mean state in El Niño and La Niña years from that

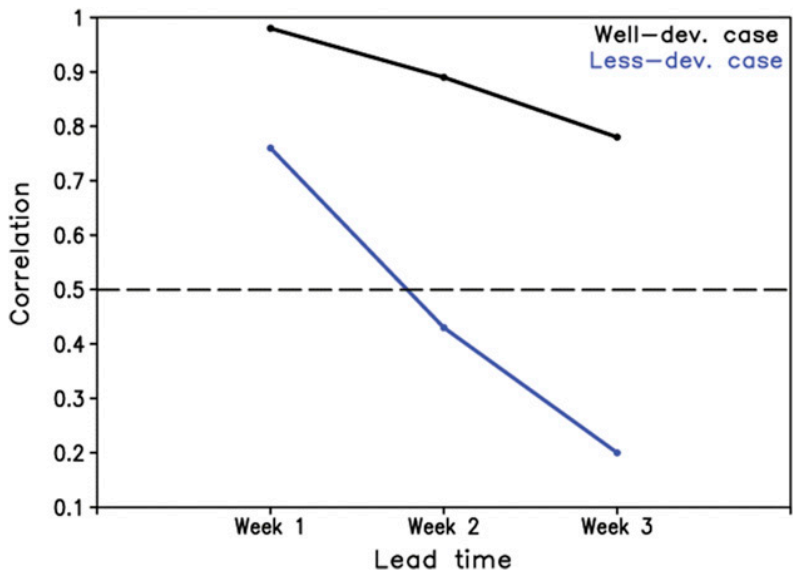

FIG. 8. Spatial correlation coefficients of the anomalous streamfunction at $200 \mathrm{hPa}$ over the Northern Hemisphere $\left(15^{\circ}-80^{\circ} \mathrm{N}\right.$, $0^{\circ}-360^{\circ}$ ) between observations and the GloSea5 simulation. The correlation coefficients are given as functions of the forecast lead time and for well- (black) and less-developed (blue) MJO cases, respectively. The values are averaged for all MJO phases and for all winter cases. The well-developed cases include the initial MJO amplitudes that are more than 1.0 and the less-developed cases under 1.0 
(a) Observation (Neutral)

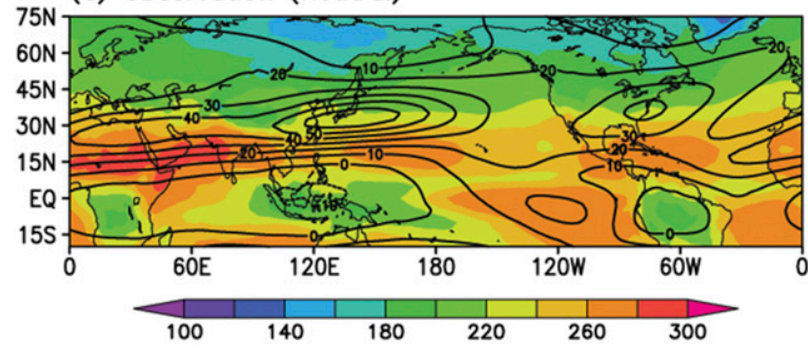

(c) Observation (EI Nino-Neutral)

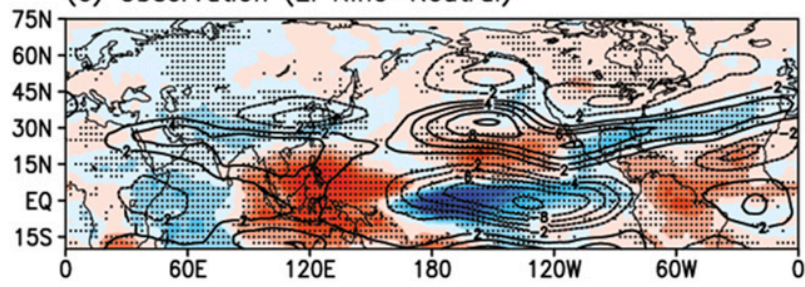

(e) Observation (La Nina-Neutral)

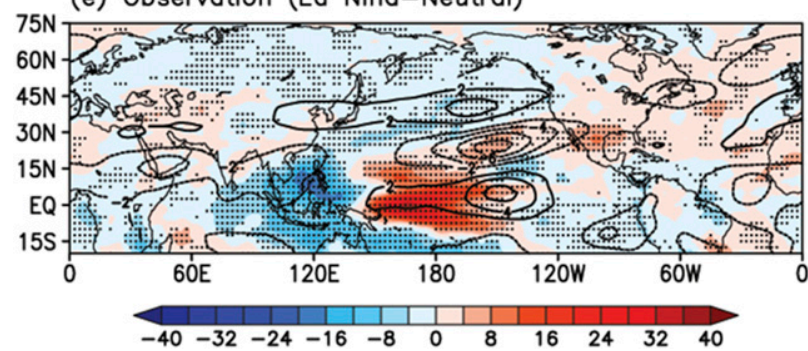

(b) GloSea5 (Neutral)

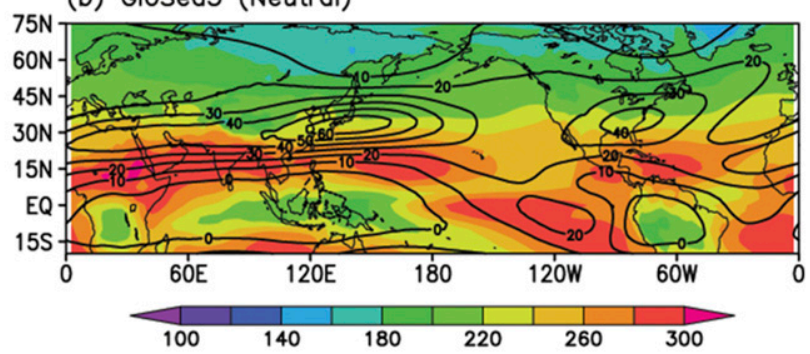

(d) GloSea5 (EI Nino-Neutral)

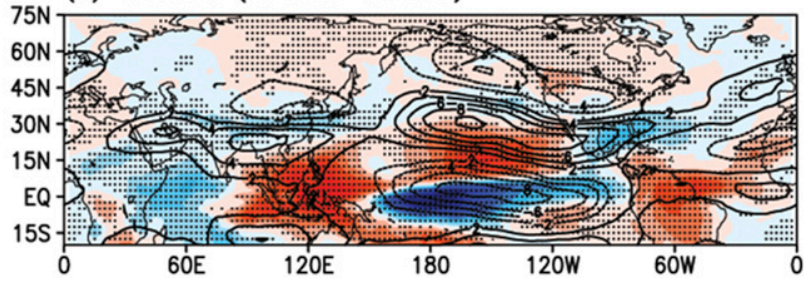

(f) GloSea5 (La Nina-Neutral)

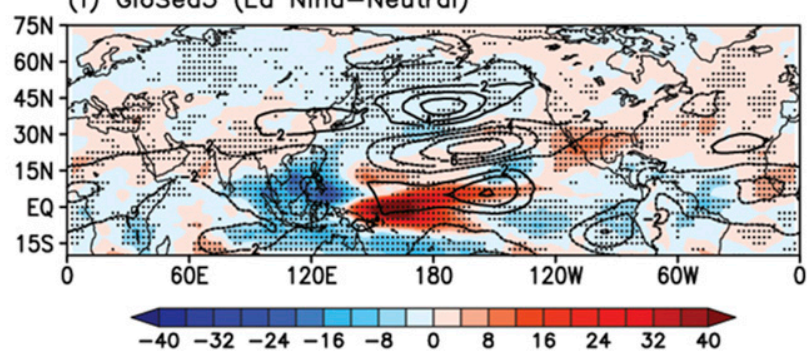

FIG. 9. (a),(b) Winter-mean OLR (shading; $\mathrm{W} \mathrm{m}^{-2}$ ) and U200 (contours; $\mathrm{m} \mathrm{s}^{-1}$ ) for neutral years. Deviation of winter-mean OLR and U200 for (c),(d) El Niño and (e),(f) La Niña years from neutral years. Results are shown for (left) the observations and (right) GloSea5 week 2. Black dotted areas are statistically significant at the 5\% level for OLR anomalies based on a two-tailed Student's $t$ test.

in the neutral years. During the neutral years, relatively low values of seasonal mean OLR in the tropics feature areas of deep convection: the Indo-Pacific warm pool and tropical landmasses. The mean U200 pattern in the neutral years (Fig. 9a) shows subtropical jets in South Asia and the western North Pacific, as well as in the North Atlantic. The corresponding observed stationary total wavenumber (Ks), which is one of the key factors that determines the ray path of the stationary Rossby waves (e.g., Seo and Lee 2017), shows a waveguide following the subtropical jets in the Eastern Hemisphere and relatively lower values of Ks in the eastern Pacific (Fig. 10a). The stationary Rossby wave theory (Hoskins and Karoly 1981) predicts that the planetary-scale Rossby waves with zonal wavenumbers smaller than 5 can propagate north beyond the Asia-Pacific subtropical jet only in the eastern Pacific region. GloSea5 realistically captures the observed mean state of OLR, U200, and Ks in the neutral years, though the OLR value in the subtropics is a bit too high.

During El Niño years, anomalously enhanced and suppressed convection develop over the central Pacific and the Maritime Continent, respectively. Associated with the changes in the distribution of tropical deep convection, the subtropical jet streams, especially that in the North Pacific, shift southward and become more zonally elongated (Fig. 9c). The changes in U200 during El Niño years result in a decrease in Ks in the northeast Pacific $\left(40^{\circ}-50^{\circ} \mathrm{N}, 180^{\circ}-120^{\circ} \mathrm{W}\right)$, which would ease propagation of the stationary Rossby waves through the area (Fig. 10c). During La Niña years, the changes in the mean OLR, U200, and Ks are nearly similar to those during El Niño years, with the signs reversed. This means that the tropical convection is more vigorous over the Maritime Continent, that the subtropical jets move northward and zonally shrink, and that Ks in the northeast Pacific tends to increase (Figs. 9e and 10e). The GloSea5 results show a noticeable resemblance to the observed patterns. This result may not be surprising as the oceanic SST anomalies associated with ENSO are initialized with high accuracy in the current ensemble seasonal forecasting systems. Overall, the comparison results indicate that GloSea5 reproduces the ENSO-related interannual variability of the mean OLR and U200 realistically during winter. 
(a) Observation (Neutral)

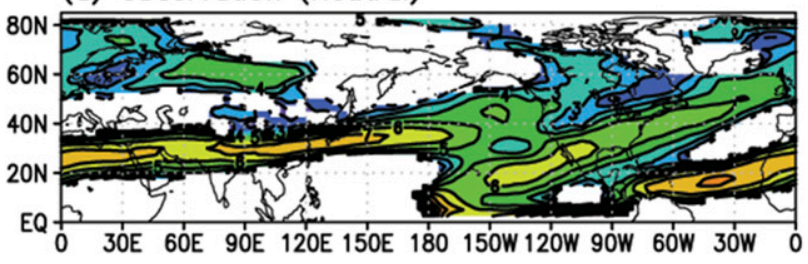

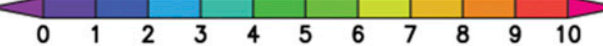

(c) Observation (EI Nino-Neutral)

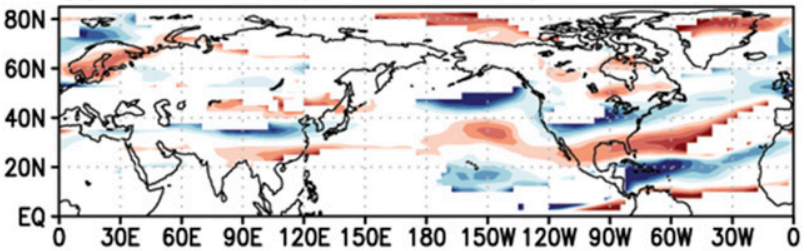

(e) Observation (La Nina-Neutral)
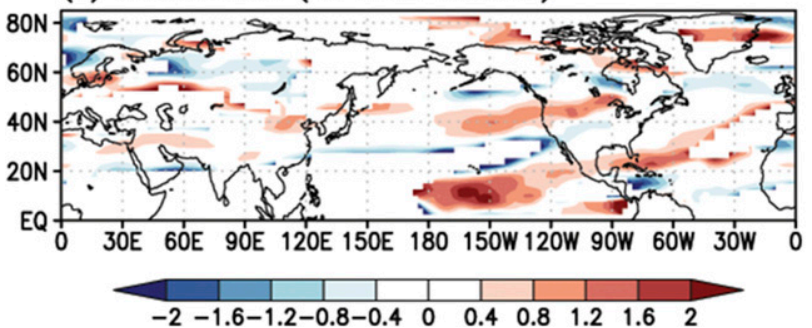

(b) GloSea5 (Neutral)

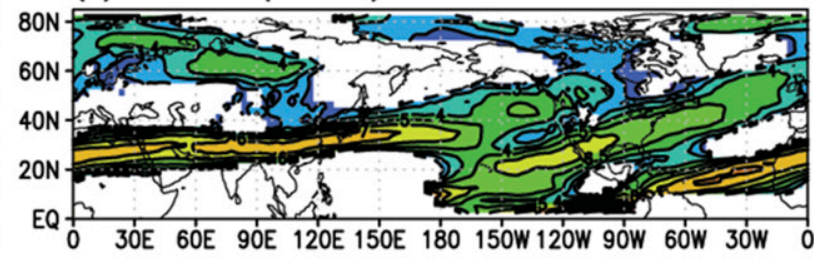

\begin{tabular}{llllllllllllll}
\hline & & & & & & & & & & & & \\
\hline & 1 & 2 & 3 & 4 & 5 & 6 & 7 & 8 & 9 & 10
\end{tabular}

(d) GloSea5 (El Nino-Neutral)

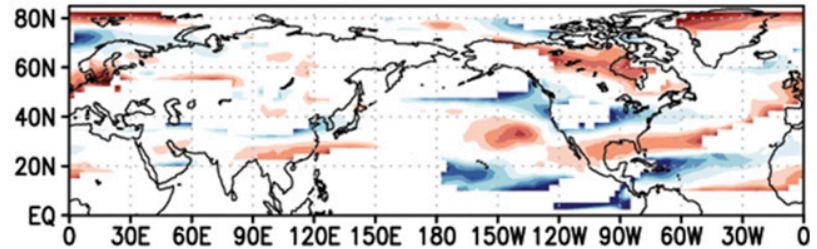

(f) GloSea5 (La Nina-Neutral)

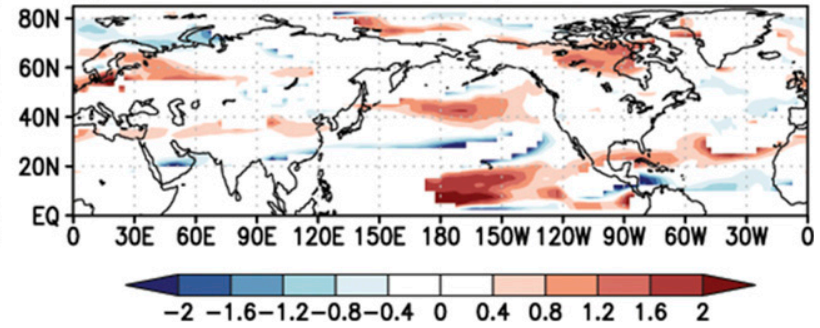

FIG. 10. (a),(b) Winter-mean stationary wavenumber for neutral years. Deviation of winter-mean stationary wavenumber for (c),(d) El Niño and (e),(f) La Niña years from the neutral years. Results are shown for (left) the observations and (right) GloSea5 week 2.

Figures 11a and 11b show the observed and the simulated intraseasonal variance of OLR during boreal winter. The observed variance is large over the Indo-Pacific warm pool, especially the oceanic areas in the Maritime Continent, in the South Pacific convergence zone (SPCZ) region, and in the Australian monsoon region. GloSea5 is capable of capturing most of these high-variance regions realistically. The difference between El Niño (La Niña) and neutral years shows that the intraseasonal OLR variance increases (decreases) over the central Pacific while it decreases (increases) in the northern Indian Ocean and in the subtropical Pacific Ocean during El Niño (La Niña) years. GloSea5 reproduces the observed features reasonably well, although the magnitude is weak in the northern and the southern Indian Ocean, but large in the northern subtropical Pacific. Forecast deficiencies in the MJO teleconnection with respect to the ENSO cycle may be influenced by incorrect ENSO impacts on the anomalous convection and upper-level circulation on intraseasonal time scales.

\section{c. Sensitivity of MJO prediction skill and $M J O$ teleconnection to ENSO phase}

We explore in this section the possibility that the ENSO-associated changes in the mean state could affect the representation of the $\mathrm{MJO}$ and its teleconnection in GloSea5. It would be of interest to see whether there is any association between MJO prediction skill and MJO teleconnection performance in GloSea5. If the distribution of tropical heating anomalies plays an important role in determining the teleconnection pattern, MJO teleconnection performance would be higher in years with better MJO skill. If the basic state in the midlatitudes (Ks) is more important than the anomalous diabatic heating in shaping the teleconnection patterns, the association between MJO prediction skill and MJO teleconnection performance would be weak.

Figure 12 compares the MJO prediction skill in GloSea5 among the El Niño, La Niña, and neutral years. During the first week of the hindcast (days 1-7), the skill is higher in the neutral years than in the other years. During the following days, the skill is relatively lower in El Niño years. The relatively lower MJO skill in the El Niño years can be attributed to relatively poor representations of OLR and U200 anomalies (Fig. 13).

Figure 14 shows anomalous OLR and upper- and lower-level circulations in the observations and in the GloSea5 hindcasts during the neutral, El Niño, and La Niña years, shown for MJO phase 3. In all cases, the 
(a) Observation (Neutral)

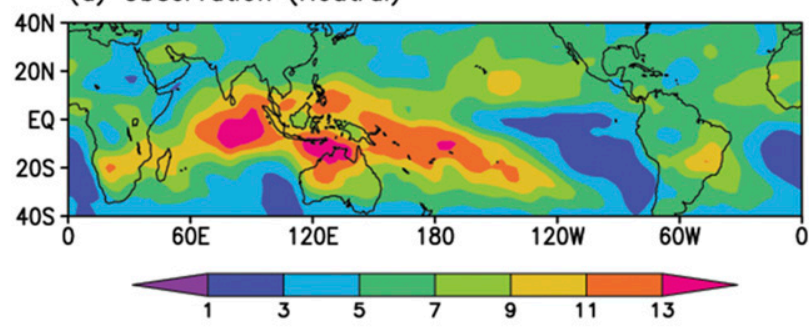

(c) Observation (El Nino-Neutral)

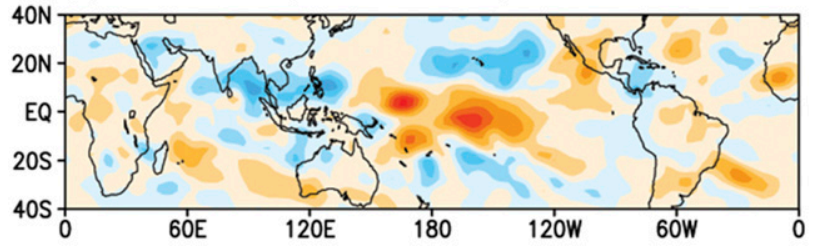

(e) Observation (La Nina-Neutral)

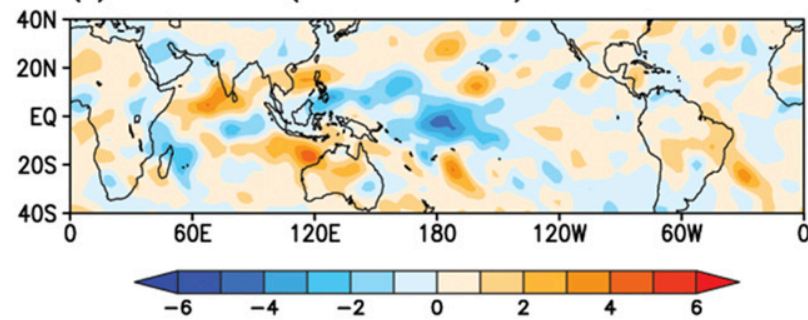

(b) GloSea5 (Neutral)

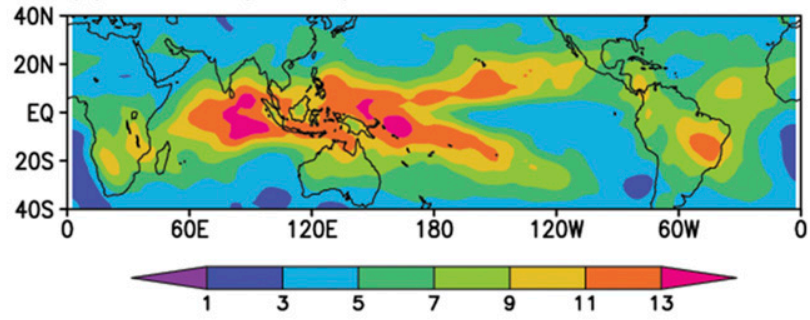

(d) GloSea5 (EI Nino-Neutral)

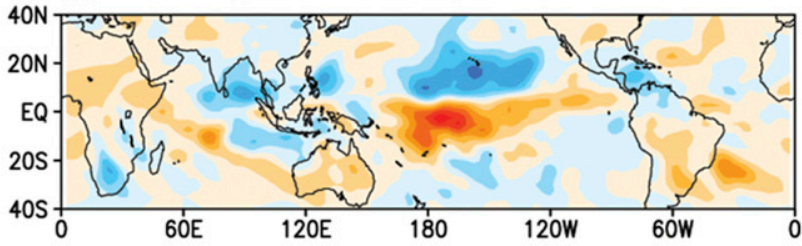

(f) GloSea5 (La Nina-Neutral)

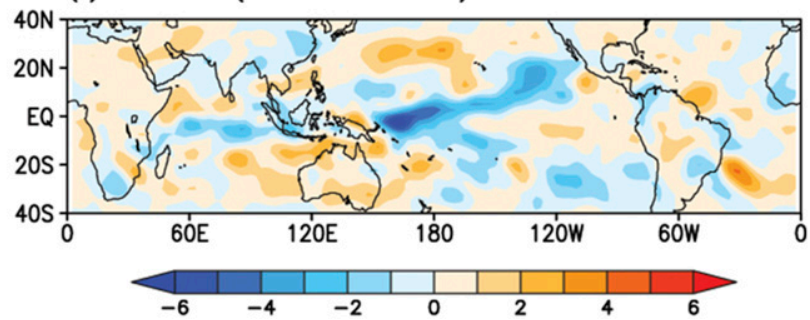

FIG. 11. (a),(b) Climatological winter mean intraseasonal variability (ISV) of OLR $\left(\mathrm{W} \mathrm{m}^{-2}\right.$ ) for neutral years. Deviation of OLR ISV for (c),(d) El Niño and (e),(f) La Niña years from the neutral years. Results are shown for (left) the observations and (right) GloSea5 week 2.

anomalous convection over the Indian Ocean and the western Pacific induces a quadruple pattern of upperlevel circulation anomalies within $30^{\circ} \mathrm{S}-30^{\circ} \mathrm{N}$. This quadruple pattern consists of the twin (symmetric about the equator) anticyclonic circulation anomalies to the west of the convection, one centered over India and the other over the southern Indian and Africa, and the twin cyclonic circulation anomalies to the east of the suppressed convection, one over the central Pacific and the other over western Australia. This is a well-known Gilltype response to the dipole diabatic heating anomalies associated with MJO (Rui and Wang 1990; Adames and Wallace 2014). It is also accompanied by extratropical wave-like responses, for example, a widespread wave (a) ACC

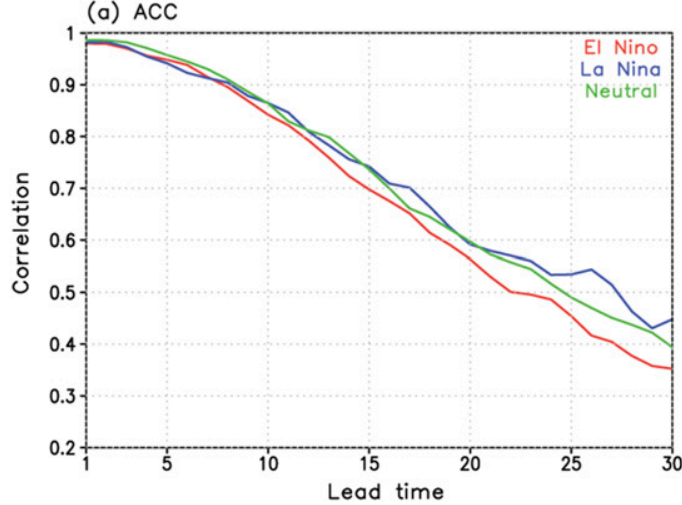

(b) RMSE

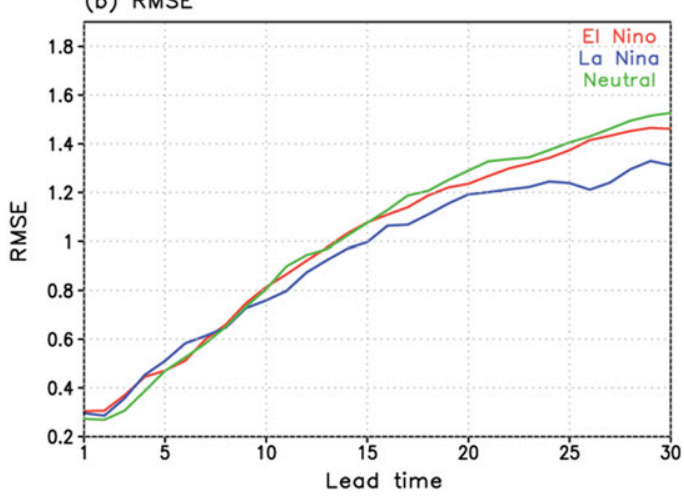

FIG. 12. Bivariate (a) ACCs and (b) RMSEs of GloSea5 RMM indices as a function of forecast lead time. Bivariate ACCs and RMSEs are obtained by using MJO cases during boreal winter for El Niño (red), La Niña (blue), and neutral (green) years, respectively. 

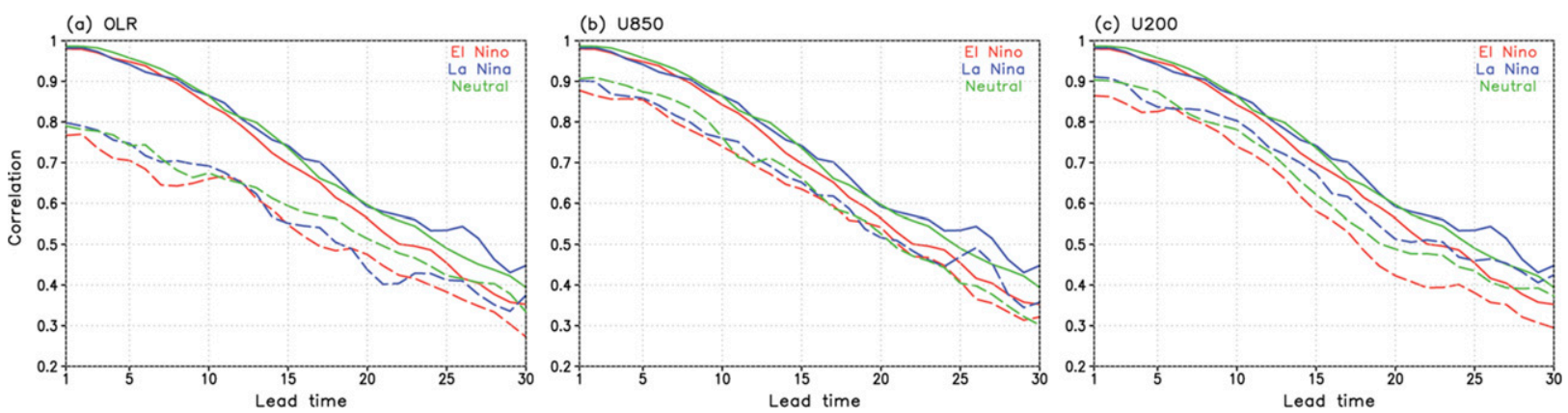

FIG. 13. Bivariate ACCs of GloSea5 RMM indices during boreal winter for El Niño (red), La Niña (blue), and neutral (green) years as a function of forecast lead time. Solid and dashed lines in each panel indicate the results obtained using the original RMM indices and the reconstructed RMM indices using only (a) OLR, (b) 850-hPa zonal wind, and (c) 200-hPa zonal wind, respectively.

train emanating toward the North Pacific from the central Pacific.

For MJO phase 3, notable differences among the neutral, El Niño, and La Niña years in OLR anomalies appear in the western Pacific. The positive OLR anomalies in the western Pacific in the El Niño (La Niña) years are located to the east (west) of those in the neutral years, presumably because of the positive (negative) SST anomalies in the central Pacific during the El Niño (La Niña) years and associated changes in the Walker circulation. On the contrary, the anomalously convective conditions over the Indian Ocean appear similarly regardless of ENSO phase. GloSea5 (Figs. 14b,d,f) captures the zonal shift in the suppressed conditions in the western Pacific, while it tends to underestimate the negative OLR anomalies in the Indian Ocean. Another noteworthy bias in OLR anomalies in GloSea5 is the weaker-than-observed west Pacific OLR anomalies during the El Niño and La Niña years.

In regard to the midlatitude teleconnection pattern, the El Niño MJO phase 3 teleconnection pattern is (a) Observation (Phase 3, Neutral)

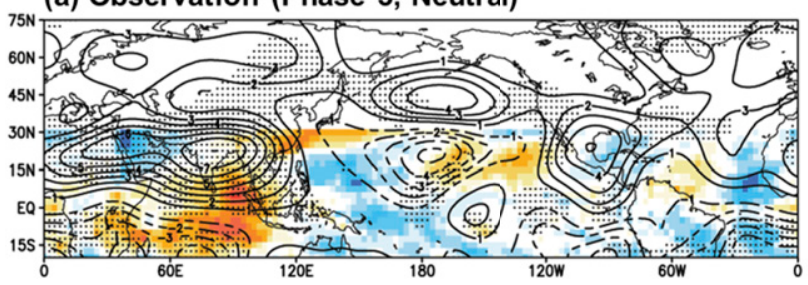

(c) Observation (Phase 3, El Nino)

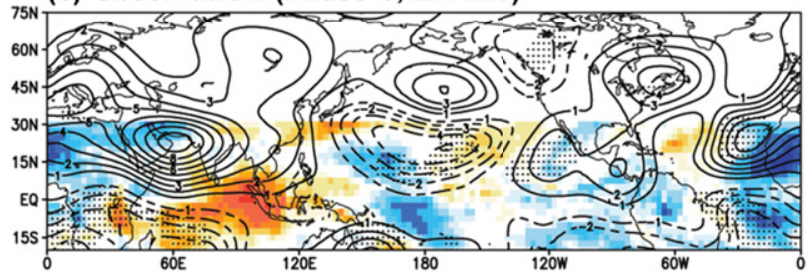

(e) Observation (Phase 3, La Nina)

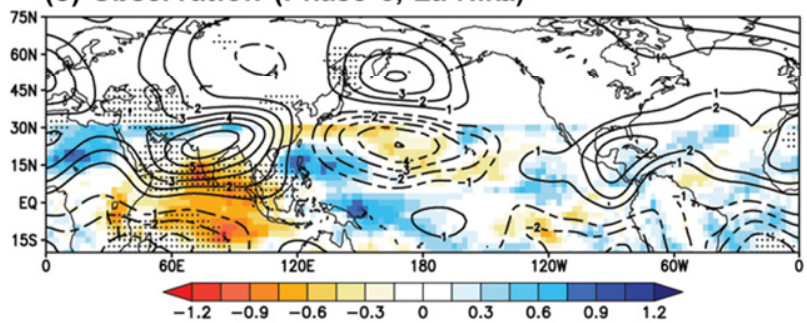

(b) GloSea5 (Phase 3, Neutral)

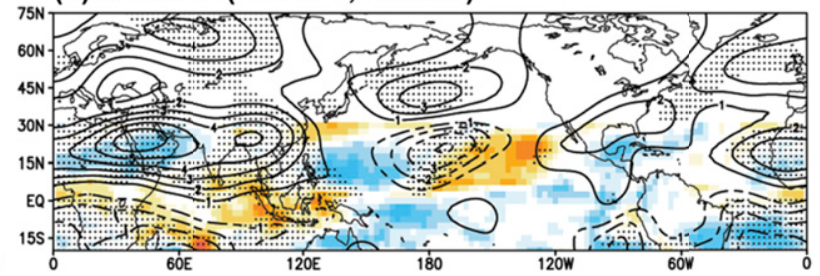

(d) GloSea5 (Phase 3, El Nino)

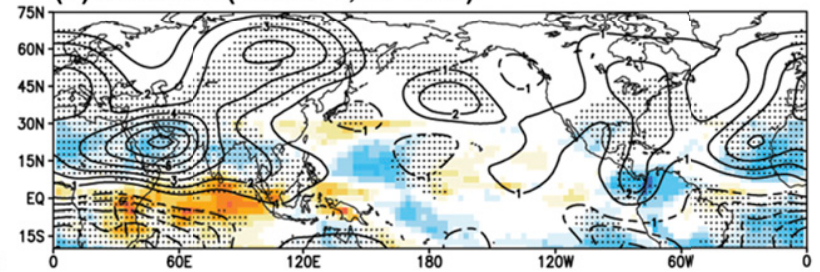

(f) GloSea5 (Phase 3, La Nina)

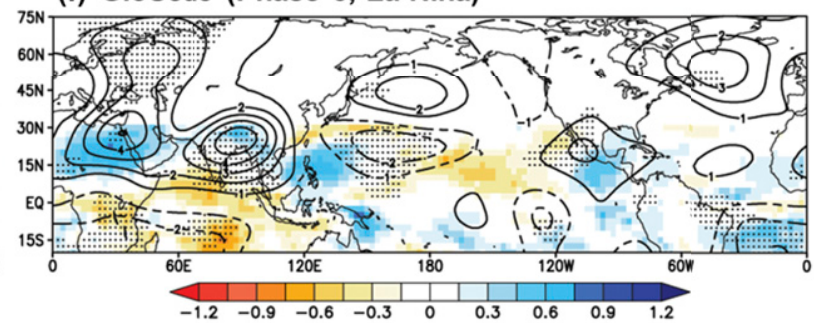

FIG. 14. Composite of OLR (shading; $\mathrm{W} \mathrm{m}^{-2}$ ) and streamfunction at $200 \mathrm{hPa}$ (contours; $10^{-6} \mathrm{~m} \mathrm{~s}^{-1}$ ) anomalies at MJO phase 3 during (a),(b) neutral, (c),(d) El Niño, and (e),(f) La Niña years during boreal winter. Results are shown for (left) the observations and (right) the hindcasts during week 2. Each variable was filtered for 30-70 days. Black dotted areas are statistically significant at the 5\% level for 200-hPa streamfunction anomalies based on two-tailed bootstrap testing. 
(a) Observation (Phase 7, Neutral)

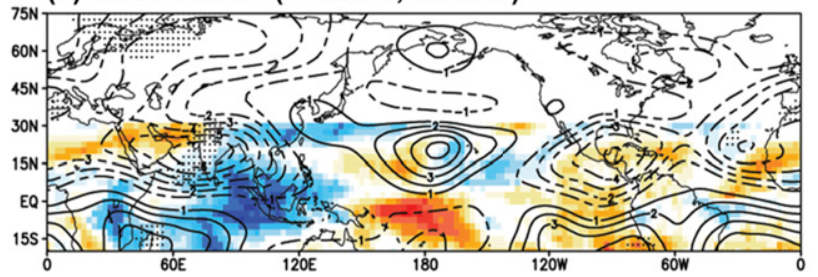

(c) Observation (Phase 7, El Nino)

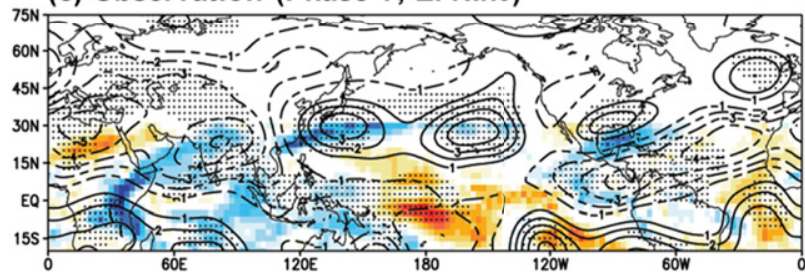

(e) Observation (Phase 7, La Nina)

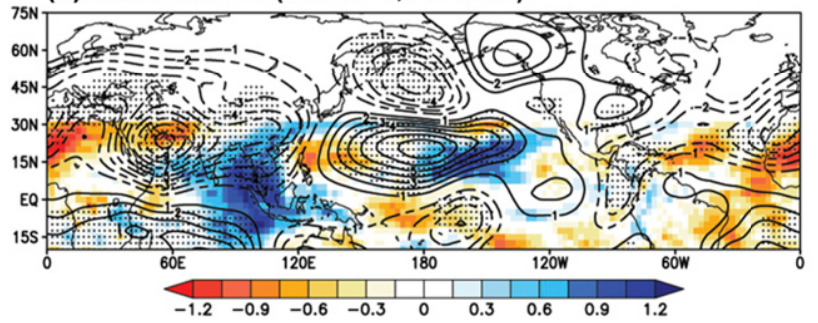

(b) GloSea5 (Phase 7, Neutral)

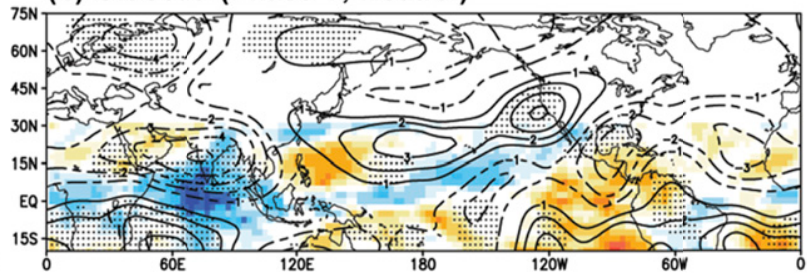

(d) GloSea5 (Phase 7, El Nino)

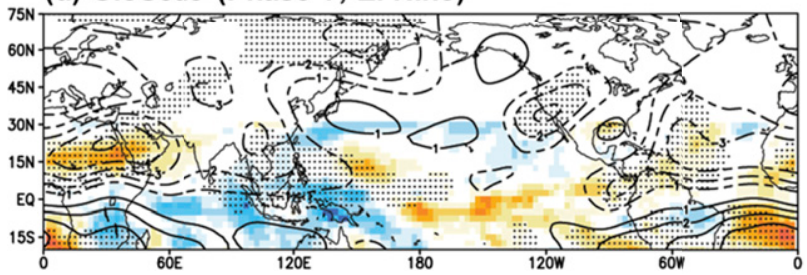

(f) GloSea5 (Phase 7, La Nina)

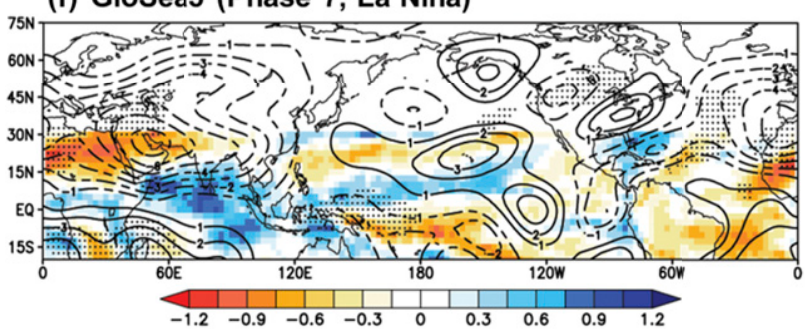

FIG. 15. As in Fig. 14, but for MJO phase 7.

distinguished from that in the neutral years by the bent path of the Pacific wave train to the north of about $45^{\circ} \mathrm{N}$, with a hint of a turning latitude near $60^{\circ} \mathrm{N}$. It seems that the zonal position of the Pacific wave train is not affected by the eastward shift of enhanced convection in the western Pacific, suggesting that the changes in the midlatitude basic state (e.g., Ks) are the key to understanding the differences in the teleconnection pattern between the El Niño and neutral years. Indeed, Ks in the northeast Pacific is lower during the El Niño years than during the neutral years (Fig. 10), which could cause a southward shift of the turning latitude. During the La Niña years, the path of the Pacific wave train is shifted westward compared to that during the neutral years, possibly because of the zonal contraction of the Pacific subtropical jet. It has been suggested that the jet-exit region, in which the barotropic energy conversion from the mean to eddies is efficient, is a preferred area of enhanced poleward propagation of Rossby waves (e.g., Adames and Wallace 2014). According to this hypothesis, therefore, the westward shift in the zonal position of the Pacific wave train can be explained as a result of the westward shift in the jet-exit region during the La Niña years. It also seems possible that the westward shift of the Pacific wave train is a direct result of the westward shift in the enhanced convection in the western Pacific.
The observed MJO teleconnection patterns in Fig. 14 have much resemblance to the results in Moon et al. (2011), with some minor differences presumably due to the differences in the analysis periods.

GloSea5 (Figs. 14b, 14d, and 14f) tends to realistically reproduce the phase $3 \mathrm{MJO}$ teleconnection patterns in all ENSO phases, although the circulation anomalies are much weaker than that in the observations. In particular, during the El Niño years, the Pacific subtropical low is hardly reproduced, which seems to be responsible for the poor representation of the Pacific wave train. The weaker Pacific teleconnection pattern during the El Niño years in GloSea5 seems to be related to the weaker-than-observed OLR anomalies in the western Pacific. The circulation anomalies over the Pacific are reproduced better during the neutral and the La Niña years, when the suppressed convection signal over the western Pacific is more realistic than during the El Niño years.

At MJO phase 7 during the neutral years (Fig. 15a), when the positive and negative convection anomalies are located over the western Pacific and the Indian Ocean, respectively, the observations show the quadruple pattern of the intraseasonal SF200 anomalies, with the symmetric twin cyclones to the west of the Indian Ocean, and the twin anticyclones in the central 


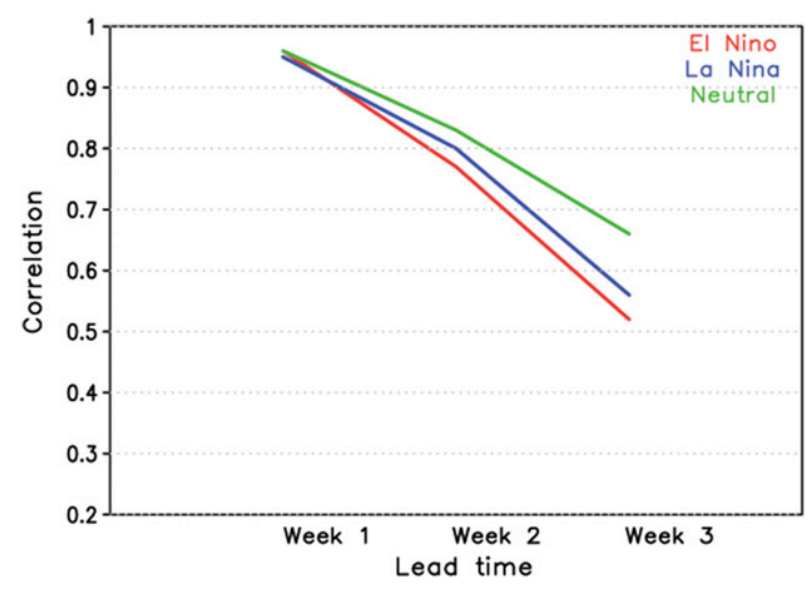

FIG. 16. Spatial correlation coefficients of the simulated streamfunction anomaly at $200 \mathrm{hPa}$ with the observed anomaly over the Northern Hemisphere $\left(15^{\circ}-80^{\circ} \mathrm{N}, 0^{\circ}-360^{\circ}\right)$ as a function of MJO phase for weeks 1 (lead time 1-8 days), 2 (lead time 9-16 days), and 3 (lead time 17-24 days). The coefficients are averaged over all MJO phases in well-developed MJO cases for each ENSO phase. Red, blue, and green lines are for El Niño, La Niña, and neutral years, respectively.

Pacific; these trends are reversed to the case of MJO phase 3. During El Niño, the MJO phase 7 teleconnection pattern appearing in the intraseasonal SF200 anomalies is confined within the subtropical North Pacific, presumably related with the persistently extended subtropical Pacific jet stream during El Niño. This suggests that the impacts of jet stream changes on the MJO teleconnection pattern are stronger for MJO phase 7 than for MJO 3. The teleconnection pattern during the La Niña years is shifted to the west as the subtropical jet zonally retreats. The GloSea5 representations of the intraseasonal SF200 anomalies over the central Pacific and North America are more realistic for the neutral and the La Niña cases. In short, the extratropical responses in the upper-level circulations and their dependence on the ENSO phase are captured reasonably well in GloSea5 in spite of the overall weak amplitude in the teleconnection pattern. This relationship between the upper-level zonal wind and the MJO teleconnection pattern was described in Henderson et al. (2017) using CMIP5 model simulations. Locations of the teleconnection patterns are largely determined by the zonal wind or jet stream acting as a waveguide. Therefore, changes to the subtropical jet stream according to ENSO phase modulates the location of the MJO teleconnection pattern significantly.

When all MJO phases are considered, the MJO teleconnection is better represented during the neutral years than during the El Niño and La Niña years (Fig. 16). That GloSea5 exhibits a superior performance of MJO teleconnection during the neutral years is consistent with our examination of individual MJO phases
(Figs. 14 and 15). It is also interesting to see that MJO prediction skill is also higher during the neutral years than during the El Niño and La Niña years (Figs. 12 and 13). Therefore, the representation of the MJO diabatic heating in the tropics is one of the key elements for improving the MJO teleconnection performance in response to the ENSO conditions in GloSea5.

\section{Summary and conclusions}

This paper evaluates MJO prediction skill and MJO teleconnection performance in the KMA version of the Global Seasonal Forecasting System, version 5 (GloSea5). In particular, this study also examines the sensitivity of MJO prediction skill and MJO teleconnection patterns to ENSO conditions. For evaluation, the Real-Time Multivariate MJO (RMM) index, and two metrics of the MJO prediction skill, the bivariate ACC and the RMSE, are used. The reproduction skill of the MJO teleconnection by the forecast system is measured using spatial pattern correlation coefficients.

GloSea5 exhibits forecast skill for the MJO index up to 24 days and represents weak sensitivity of the skill to initial MJO phase although the skill is relatively higher (lower) when the initial phase of the MJO is 2 or 3 ( 8 or 1) during the first 2 weeks of the lead time. The reconstructed RMM indices with the wind variables show higher prediction skill than that with OLR, suggesting that the MJO prediction skill could be enhanced by improving the representation of the convective anomalies associated with MJO in GloSea5. The eastwardpropagating patterns of OLR and low-level wind anomalies in the tropics were examined, and the results show that the hindcasts have difficulty in representing eastward propagation patterns of tropical convection and wind anomalies initiated over the western Pacific. In addition, the propagation speed and amplitude of the $\mathrm{MJO}$ are slower and weaker than are observed.

We investigate to what degree the upper-level circulation in the extratropics is modulated by the tropical MJO by presenting the percentage variance of the upper-level circulation anomalies that can be explained by the RMM index. In the observations, the percentage variance is the largest in the subtropics, especially over the Indo-Pacific warm pool region in the Eastern Hemisphere where the MJO becomes most active. Furthermore, there is higher variance in the midlatitudes, such as in the North Pacific, Alaska, and the eastern part of North America. GloSea5 reproduces similar spatial distributions of the percentage variance. However, the values are underestimated across both the subtropics and extratropics, and the variances over Alaska and the eastern part of North America are not 
described properly. This might be related to model deficiencies in simulating the intensity of the winter-mean intraseasonal variability of OLR and upper-level circulation.

ENSO alters background fields, for instance, sea surface temperature and upper-level wind, and this could have an influence on the MJO activity and horizontal propagation of Rossby waves. Thus, the reproducibility of the convective activity and the circulation field at $200 \mathrm{hPa}$ from the hindcasts at various time scale is investigated. The forecast system describes realistically different patterns of the climatological winter mean and intraseasonal variability of OLR between El Niño and La Niña although the peak of the simulated OLR intraseasonal variability over the tropics is shifted southward in comparison with the observations.

The sensitivity of the MJO prediction skill to the ENSO phase is explored using GloSea5. The skill in the neutral years is higher than that during other ENSO phases during the first week, but then the skill in El Niño years becomes low. This is thought to be due to inappropriate reproductions of OLR and U200 in the forecast system.

The MJO teleconnection patterns from the observations and the hindcasts are compared for boreal winter during neutral, El Niño, and La Niña years for MJO phases 3 and 7. For MJO phase 3, the suppressed convection anomalies in the western Pacific during the El Niño years are located to the east of those during the neutral years, and the MJO teleconnection pattern shows the bent path of the Pacific wave train as compared to that during the neutral years. This can be explained by the changes to Ks, not the change of the anomalous convection over the tropics. During La Niña years, the positive OLR anomalies in the western Pacific appear in the east rather than those in the neutral years, and the teleconnection pattern is shifted to the west of that during the neutral years due to the westward contraction of the Pacific subtropical jet. During MJO phase 7 , most MJO teleconnection patterns are located only over the Pacific, especially over the subtropics during El Niño years, and this might be associated with the zonally extended subtropical jet. During La Niña years, the teleconnection pattern is shifted westward for the same reason as in MJO phase 3 during La Niña years. GloSea5 tends to describe the distribution of the observed OLR anomaly over the west Pacific realistically although there are underestimations of the tropical OLR anomaly during both phases 3 and 7. MJO teleconnection patterns are also reasonably represented except for those during the El Niño years, which might be related to the weaker OLR anomalies in the west Pacific than that in the observation.
When all MJO phases are considered, the reproducibility of the MJO teleconnection is higher during the neutral years than during the El Niño and La Niña years when the coefficients are averaged over all MJO phases in well-developed MJO cases, and this is consistent with the results for MJO prediction skill. These results suggest that the representation of the tropical diabatic heating in response to ENSO is one of the key elements for improving the MJO teleconnection patterns in the dynamical prediction system. Our study warrants further investigation of the relationship among ENSO, $\mathrm{MJO}$, and MJO teleconnections in operational hindcast datasets, such as those involved in the Subseasonal-toSeasonal (S2S) Prediction Project (Vitart et al. 2017).

Acknowledgments. This study was funded by the Korea Meteorological Administration Research and Development Program "Research and Development for KMA Weather, Climate, and Earth system ServicesDevelopment of Climate Prediction System" under Grant KMA2018-00322.

\section{REFERENCES}

Adames, Á. F., and J. M. Wallace, 2014: Three-dimensional structure and evolution of the MJO and its relation to the mean flow. J. Atmos. Sci., 71, 2007-2026, https://doi.org/ 10.1175/JAS-D-13-0254.1.

Baxter, S., S. Weaver, J. Gottschalck, and Y. Xue, 2014: Pentad evolution of wintertime impacts of the Madden-Julian oscillation over the contiguous United States. J. Climate, 27, 73567367, https://doi.org/10.1175/JCLI-D-14-00105.1.

Bergman, J. W., H. H. Hendon, and K. M. Weickmann, 2001: Intraseasonal air-sea interactions at the onset of El Niño. J. Climate, 14, 1702-1719, https://doi.org/10.1175/1520-0442(2001)014<1702: IASIAT $>2.0 . \mathrm{CO} ; 2$.

Best, M. J., and Coauthors, 2011: The Joint UK Land Environment Simulator (JULES), model description-Part 1: Energy and water fluxes. Geosci. Model Dev., 4, 677-699, https://doi.org/ 10.5194/gmd-4-677-2011.

Brown, A., S. Milton, M. Cullen, B. Golding, J. Mitchell, and A. Shelly, 2012: Unified modeling and prediction of weather and climate: A 25-year journey. Bull. Amer. Meteor. Soc., 93, 1865-1877, https://doi.org/10.1175/BAMS-D-12-00018.1.

Gottschalck, J., and Coauthors, 2010: A framework for assessing operational Madden-Julian oscillation forecasts: A CLIVAR MJO Working Group Project. Bull. Amer. Meteor. Soc., 91, 1247-1258, https://doi.org/10.1175/2010BAMS2816.1.

Henderson, S. A., E. D. Maloney, and S.-W. Son, 2017: Madden-Julian oscillation Pacific teleconnections: The impact of the basic state and MJO representation in general circulation models. J. Climate, 30, 4567-4587, https://doi.org/10.1175/JCLI-D-16-0789.1.

Hewitt, H. T., D. Copsey, I. D. Culverwell, C. M. Harris, R. S. R. Hill, A. B. Keen, A. J. McLaren, and E. C. Hunke, 2011: Design and implementation of the infrastructure of HadGEM3: The next-generation Met Office climate modelling system. Geosci. Model Dev., 4, 223-253, https://doi.org/ 10.5194/gmd-4-223-2011. 
Hoskins, B. J., and D. J. Karoly, 1981: The steady linear response of a spherical atmosphere to thermal and orographic forcing. J. Atmos. Sci., 38, 1179-1196, https://doi.org/ 10.1175/1520-0469(1981)038<1179:TSLROA > 2.0.CO;2.

_- , and T. Ambrizzi, 1993: Rossby wave propagation on a realistic longitudinally varying flow. J. Atmos. Sci., 50, 1661-1671, https://doi.org/10.1175/1520-0469(1993)050<1661: RWPOAR $>2.0 . \mathrm{CO} ; 2$.

Hunke, E. C., and W. H. Lipscomb, 2010: CICE: The Los Alamos Sea Ice Model documentation and software user's manual, version 4.1. Los Alamos National Laboratory Tech. Rep. LA-CC-06-012, 76 pp., https://csdms.colorado.edu/w/images/ CICE_documentation_and_software_user\%27s_manual.pdf.

Jeong, J.-H., B.-M. Kim, C.-H. Ho, and Y.-H. Noh, 2008: Systematic variation in wintertime precipitation in East Asia by MJOinduced extratropical vertical motion. J. Climate, 21, 788-801, https://doi.org/10.1175/2007JCLI1801.1.

Jia, X., C. Lijuan, R. Fumin, and L. Chongyin, 2011: Impacts of the MJO on winter rainfall and circulation in China. Adv. Atmos. Sci., 28, 521-533, https://doi.org/10.1007/s00376-010-9118-z.

Johnson, N. C., D. C. Collins, S. B. Feldstein, M. L. L'Heureux, and E. E. Riddle, 2014: Skillful wintertime North American temperature forecasts out to 4 weeks based on the state of ENSO and the MJO. Wea. Forecasting, 29, 23-38, https://doi.org/ 10.1175/WAF-D-13-00102.1.

Kessler, W., and R. Kleeman, 2000: Rectification of the Madden-Julian oscillation into the ENSO cycle. J. Climate, 13, 3560-3575, https:// doi.org/10.1175/1520-0442(2000)013<3560:ROTMJO>2.0.CO;2.

Kim, D., M.-I. Lee, H.-M. Kim, S. D. Schubert, and J. H. Yoo, 2014: The modulation of tropical storm activity in the western North Pacific by the Madden-Julian oscillation in GEOS-5 AGCM experiments. Atmos. Sci. Lett., 15, 335-341, https://doi.org/ 10.1002/asl2.509.

Kim, H.-M., and I.-S. Kang, 2008: The impact of ocean-atmosphere coupling on the predictability of boreal summer intraseasonal oscillation. Climate Dyn., 31, 859-870, https://doi.org/10.1007/ s00382-008-0409-3.

_ and prediction skill of the MJO in two operational forecasting systems. J. Climate, 27, 5364-5378, https://doi.org/10.1175/ JCLI-D-13-00480.1.

Klotzbach, P. J., 2010: On the Madden-Julian oscillation-Atlantic hurricane relationship. J. Climate, 23, 282-293, https://doi.org/ 10.1175/2009JCLI2978.1.

Lau, K. M., and P. H. Chan, 1986: Aspects of the 40-50 day oscillation during the northern summer as inferred from the outgoing longwave radiation. Mon. Wea. Rev., 114, 1354-1367, https://doi.org/ 10.1175/1520-0493(1986)114<1354:AOTDOD > 2.0.CO;2.

Lee, M.-I., H.-S. Kang, D. Kim, D. Kim, H. Kim, and D. Kang, 2014: Validation of the experimental hindcasts produced by the GloSea5 seasonal prediction system. Asia-Pac. J. Atmos. Sci., 50, 307-326, https://doi.org/10.1007/s13143-014-0019-4.

Lim, Y., S. Son, and D. Kim, 2018: MJO prediction skill of the Subseasonal-to-Seasonal Prediction models. J. Climate, 31, 4075-4094, https://doi.org/10.1175/JCLI-D-17-0545.1.

Lin, H., G. Brunet, and J. Derome, 2008: Forecast skill of the Madden-Julian oscillation in two Canadian atmospheric models. Mon. Wea. Rev., 136, 4130-4149, https://doi.org/ 10.1175/2008MWR2459.1.

MacLachlan, C., and Coauthors, 2015: Global Seasonal Forecast System version 5 (GloSea5): A high-resolution seasonal forecast system. Quart. J. Roy. Meteor. Soc., 141, 1072-1084, https://doi.org/10.1002/qj.2396.
Madden, R. A., and P. R. Julian, 1971: Detection of a 40-50 day oscillation in the zonal wind in the tropical Pacific. J. Atmos. Sci., 28, 702-708, https://doi.org/10.1175/1520-0469(1971)028<0702: DOADOI $>2.0 . \mathrm{CO} ; 2$.

, and - 1972: Description of global-scale circulation cells in the tropics with a 40-50 day period. J. Atmos. Sci., 29, 1109-1123, https://doi.org/10.1175/1520-0469(1972)029<1109: DOGSCC $>2.0 . \mathrm{CO} ; 2$.

Madec, G., and Coauthors, 2016: NEMO Ocean Engine, version 3.6. Note du Pôle de Modelisation 27, Institut Pierre-Simon Laplace, Paris, France, 386 pp., https://www.nemo-ocean.eu/ wp-content/uploads/NEMO_book.pdf.

Maloney, E. D., and D. L. Hartmann, 2000: Modulation of eastern North Pacific hurricanes by Madden-Julian oscillation. J. Climate, 13, 1451-1460, https://doi.org/10.1175/ 1520-0442(2000)013<1451:MOENPH > 2.0.CO;2.

— and _ 2001: The Madden-Julian oscillation, barotropic dynamics, and North Pacific tropical cyclone formation. Part I: Observations. J. Atmos. Sci., 58, 2545-2558, https://doi.org/ 10.1175/1520-0469(2001)058<2545:TMJOBD>2.0.CO;2.

Matthews, A. J., B. J. Hoskins, and M. Masutani, 2004: The global response to tropical heating in the Madden-Julian oscillation during the northern winter. Quart. J. Roy. Meteor. Soc., 130, 1991-2011, https://doi.org/10.1256/qj.02.123.

McPhaden, M. J., 1999: Genesis and evolution of the 1997-1998 El Niño. Science, 283, 950-954, https://doi.org/10.1126/ science.283.5404.950.

2004: Evolution of the 2002/03 El Niño. Bull. Amer. Meteor. Soc., 85, 677-695, https://doi.org/10.1175/BAMS-85-5-677.

Megann, A. P., and Coauthors, 2014: GO 5.0: The joint NERCMet Office NEMO global ocean model for use in coupled and forced applications. Geosci. Model Dev., 7, 1069-1092, https:// doi.org/10.5194/gmd-7-1069-2014.

Moon, J.-Y., B. Wang, and K.-J. Ha, 2011: ENSO regulation of MJO teleconnection. Climate Dyn., 37, 1133-1149, https:// doi.org/10.1007/s00382-010-0902-3.

Neena, J. M., J. Y. Lee, D. Waliser, B. Wang, and X. Jiang, 2014: Predictability of the Madden-Julian oscillation in the Intraseasonal Variability Hindcast Experiment (ISVHE). J. Climate, 27, 4531-4543, https://doi.org/10.1175/JCLI-D-13-00624.1.

Pegion, K., and B. P. Kirtman, 2008: The impact of air-sea interactions on the predictability of the tropical intraseasonal oscillation. J. Climate, 21, 5870-5886, https://doi.org/10.1175/ 2008JCLI2209.1.

Rae, J. G. L., H. T. Hewitt, A. B. Keen, J. K. Ridley, A. E. West, C. M. Harris, E. C. Hunke, and D. N. Walters, 2015: Development of global sea ice 6.0 CICE configuration for the Met Office global coupled model. Geosci. Model Dev., 8, 22212230, https://doi.org/10.5194/gmdd-8-2529-2015.

Rashid, H. A., H. H. Hendon, M. C. Wheeler, and O. Alves, 2011: Prediction of the Madden-Julian oscillation with the POAMA dynamical prediction system. Climate Dyn., 36, 649-661, https://doi.org/10.1007/s00382-010-0754-x.

Reichler, T., and J. O. Roads, 2005: Long-range predictability in the tropics. Part II: 30-60-day variability. J. Climate, 18, 634650, https://doi.org/10.1175/JCLI-3295.1.

Roundy, P. E., 2014: Some aspects of Western Hemisphere circulation and the Madden-Julian oscillation. J. Atmos. Sci., 71, 2027-2039, https://doi.org/10.1175/JAS-D-13-0210.1.

Rui, H., and B. Wang, 1990: Development characteristics and dynamic structure of tropical intraseasonal convection anomalies. J. Atmos. Sci., 47, 357-379, https://doi.org/ 10.1175/1520-0469(1990)047<0357:DCADSO>2.0.CO;2. 
Sardeshmukh, P. D., and B. J. Hoskins, 1988: The generation of global rotational flow by steady idealized tropical divergence. J. Atmos. Sci., 45, 1228-1251, https://doi.org/10.1175/ 1520-0469(1988)045<1228:TGOGRF $>2.0$. CO;2.

Schreck, C. J., and J. Molinari, 2011: Tropical cyclogenesis associated with Kelvin waves and the Madden-Julian oscillation. Mon. Wea. Rev., 139, 2723-2734, https://doi.org/10.1175/ MWR-D-10-05060.1.

Seo, K.-H., 2009: Statistical-dynamical prediction of the MaddenJulian oscillation using NCEP Climate Forecast System (CFS). Int. J. Climatol., 29, 2146-2155, https://doi.org/10.1002/joc.1845.

— ENSO cycle: A study with the NCEP Global Ocean Data Assimilation. Geophys. Res. Lett., 32, L07712, https://doi.org/ 10.1029/2005GL022511.

_ , and H. Lee, 2017: Mechanisms for a PNA-like teleconnection pattern in response to the MJO. J. Atmos. Sci., 74, 1767-1781, https://doi.org/10.1175/JAS-D-16-0343.1.

Shutts, G., 2005: A kinetic energy backscatter algorithm for use in ensemble prediction systems. Quart. J. Roy. Meteor. Soc., 131, 3079-3102, https://doi.org/10.1256/qj.04.106.

Takayabu, Y. N., T. Iguchi, M. Kachi, A. Shibata, and H. Kanzawa, 1999: Abrupt termination of the 1997-98 El Niño in response to a Madden-Julian oscillation. Nature, 402, 279-282, https:// doi.org/10.1038/46254.

Tennant, W. J., G. J. Shutts, A. Arribas, and S. A. Thompson, 2011: Using a stochastic kinetic energy backscatter scheme to improve MOGREPS probabilistic prediction skill. Mon. Wea. Rev., 139, 1190-1206, https://doi.org/10.1175/2010MWR3430.1.

Valcke, S., 2013: The OASIS3 coupler: A European climate modelling community software. Geosci. Model Dev., 6, 373388, https://doi.org/10.5194/gmd-6-373-2013.

Vitart, F., 2014: Evolution of ECMWF sub-seasonal prediction skill scores. Quart. J. Roy. Meteor. Soc., 140, 1889-1899, https://doi.org/10.1002/qj.2256.

- 2017: Madden-Julian oscillation prediction and teleconnections in the S2S database. Quart. J. Roy. Meteor. Soc., 143, 2210-2220, https://doi.org/10.1002/qj.3079.

_- and F. Molteni, 2010: Simulation of the Madden-Julian oscillation and its teleconnections in the ECMWF forecast system. Quart. J. Roy. Meteor. Soc., 136, 842-855, https://doi.org/10.1002/qj.623.

—, A. Leroy, and M. C. Wheeler, 2010: A comparison of dynamical and statistical predictions of weekly tropical cyclone activity in the Southern Hemisphere. Mon. Wea. Rev., 138, 3671-3682, https://doi.org/10.1175/2010MWR3343.1.

—_, and Coauthors, 2017: The Subseasonal to Seasonal (S2S) Prediction Project database. Bull. Amer. Meteor. Soc., 98, 163173, https://doi.org/10.1175/BAMS-D-16-0017.1.

Waliser, D. E., K. M. Lau, W. Stern, and C. Jones, 2003: Potential predictability of the Madden-Julian oscillation. Bull. Amer. Meteor. Soc., 84, 33-50, https://doi.org/10.1175/ BAMS-84-1-33.

— , and Coauthors, 2006: The Experimental MJO Prediction Project. Bull. Amer. Meteor. Soc., 87, 425-431, https://doi.org/ 10.1175/BAMS-87-4-421.
Walters, D. N., and Coauthors, 2011: The Met Office Unified Model Global Atmosphere 3.0/3.1 and JULES Global Land 3.0/3.1 configurations. Geosci. Model Dev., 4, 919-941, https:// doi.org/10.5194/gmd-4-919-2011.

, and Coauthors, 2017: The Met Office Unified Model Global Atmosphere 6.0/6.1 and JULES Global Land 6.0/6.1 configurations. Geosci. Model Dev., 10, 1487-1520, https://doi.org/ 10.5194/gmd-10-1487-2017.

Wang, W., M.-P. Hung, S. J. Weaver, A. Kumar, and X. Fu, 2014: MJO prediction in the NCEP Climate Forecast System version 2. Climate Dyn., 42, 2509-2520, https://doi.org/10.1007/ s00382-013-1806-9.

Wheeler, M. C., and H. H. Hendon, 2004: An all-season real-time multivariate MJO index: Development of an index for monitoring and prediction. Mon. Wea. Rev., 132, 1917-1932, https://doi.org/ 10.1175/1520-0493(2004)132<1917:AARMMI>2.0.CO;2.

$\longrightarrow,-$, S. Cleland, H. Meinke, and A. Donald, 2009: Impacts of the Madden-Julian oscillation on Australian rainfall and circulation. J. Climate, 22, 1482-1498, https://doi.org/10.1175/ 2008JCLI2595.1.

Williams, K. D., and Coauthors, 2015: The Met Office Global Coupled model 2.0 (GC2) configuration. Geosci. Model Dev., 8, 1509-1524, https://doi.org/10.5194/gmd-8-1509-2015.

Wu, J., H. L. Ren, J. Zuo, C. Zhao, L. Chen, and Q. Li, 2016: MJO prediction skill, predictability, and teleconnection impacts in the Beijing Climate Center Atmospheric General Circulation Model. Dyn. Atmos. Oceans, 75, 78-90, https://doi.org/ 10.1016/j.dynatmoce.2016.06.001.

Xiang, B., M. Zhao, X. Jiang, S.-J. Lin, T. Li, X. Fu, and G. Vecchi, 2015: 3-4 week MJO prediction skill in a GFDL coupled model. J. Climate, 28, 5351-5364, https://doi.org/10.1175/ JCLI-D-15-0102.1.

Yasunari, T., 1979: Cloudiness fluctuations associated with the Northern Hemisphere summer monsoon. J. Meteor. Soc. Japan, 57, 227-242, https://doi.org/10.2151/jmsj1965.57.3_227.

Yoo, C., S. Park, D. Kim, J. Yoon, and H. Kim, 2015: Boreal winter MJO teleconnection in the Community Atmosphere Model version 5 with the Unified Convection parameterization. J. Climate, 28, 8135-8150, https://doi.org/10.1175/ JCLI-D-15-0022.1.

Zhang, C., and J. Gottschalck, 2002: SST anomalies of ENSO and the Madden-Julian oscillation in the equatorial $\mathrm{Pa}$ cific. J. Climate, 15, 2429-2445, https://doi.org/10.1175/ 1520-0442(2002)015<2429:SAOEAT > 2.0.CO;2.

Zhang, Q., and H. van den Dool, 2012: Relative merit of model improvement versus availability of retrospective forecasts: The case of Climate Forecast System MJO prediction. Wea. Forecasting, 27, 1045-1051, https://doi.org/10.1175/ WAF-D-11-00133.1.

Zhou, S., M. L'Heureux, S. Weaver, and A. Kumar, 2012: A composite study of the MJO influence on the surface air temperature and precipitation over the continental United States. Climate Dyn., 38, 1459-1471, https://doi.org/10.1007/ s00382-011-1001-9. 